\title{
Dopaminergic stimulation leads B-cell infiltration into the central nervous system upon autoimmunity
}

\author{
Carolina Prado ${ }^{1,2}$, Francisco Osorio-Barrios ${ }^{1}$, Paulina Falcón ${ }^{1}$, Alexandra Espinoza' ${ }^{1}$ Juan José Saez ${ }^{3}$, \\ María Isabel Yuseff ${ }^{3}$ and Rodrigo Pacheco ${ }^{1,2^{*}}$ (1)
}

\begin{abstract}
Background: Recent evidence has shown dopamine as a major regulator of inflammation. Accordingly, dopaminergic regulation of immune cells plays an important role in the physiopathology of inflammatory disorders. Multiple sclerosis (MS) is an inflammatory disease involving a $\mathrm{CD}^{+} \mathrm{T}$-cell-driven autoimmune response to central nervous system (CNS) derived antigens. Evidence from animal models has suggested that B cells play a fundamental role as antigen-presenting cells (APC) re-stimulating $C D 4^{+} T$ cells in the CNS as well as regulating T-cell response by mean of inflammatory or anti-inflammatory cytokines. Here, we addressed the role of the dopamine receptor D3 (DRD3), which displays the highest affinity for dopamine, in B cells in animal models of MS.
\end{abstract}

Methods: Mice harbouring Drd3-deficient or Drd3-sufficient B cells were generated by bone marrow transplantation into recipient mice devoid of $B$ cells. In these mice, we compared the development of experimental autoimmune encephalomyelitis (EAE) induced by immunization with a myelin oligodendrocyte glycoprotein (MOG)-derived peptide (pMOG), a model that leads to CNS-autoimmunity irrespective of the APC-function of B cells, or by immunization with full-length human MOG protein (huMOG), a model in which antigen-specific activated B cells display a fundamental APC-function in the CNS. APC-function was assessed in vitro by pulsing B cells with huMOG-coated beads and then co-culturing with MOG-specific T cells.

Results: Our data show that the selective Drd3 deficiency in B cells abolishes the disease development in the huMOG-induced EAE model. Mechanistic analysis indicates that although DRD3-signalling did not affect the APCfunction of B cells, DRD3 favours the CNS-tropism in a subset of pro-inflammatory B cells in the huMOG-induced EAE model, an effect that was associated with higher CXCR3 expression. Conversely, the results show that the selective Drd3 deficiency in B cells exacerbates the disease severity in the PMOG-induced EAE model. Further analysis shows that DRD3-stimulation increased the expression of the CNS-homing molecule CD49d in a B-cell subset with antiinflammatory features, thus attenuating EAE manifestation in the PMOG-induced EAE model.

Conclusions: Our findings demonstrate that DRD3 in B cells exerts a dual role in CNS-autoimmunity, favouring CNStropism of pro-inflammatory B cells with APC-function and promoting CNS-homing of B cells with anti-inflammatory features. Thus, these results show DRD3-signalling in B cells as a critical regulator of CNS-autoimmunity.

\footnotetext{
*Correspondence: rpachecr@gmail.com; rpacheco@cienciavida.org

${ }^{1}$ Laboratorio de Neuroinmunología, Centro Ciencia \& Vida, Fundación Ciencia \& Vida, Avenida Zañartu \#1482, Ñuñoa, 7780272 Santiago, Chile

Full list of author information is available at the end of the article
} permits use, sharing, adaptation, distribution and reproduction in any medium or format, as long as you give appropriate credit to the original author(s) and the source, provide a link to the Creative Commons licence, and indicate if changes were made. The images or other third party material in this article are included in the article's Creative Commons licence, unless indicated otherwise in a credit line to the material. If material is not included in the article's Creative Commons licence and your intended use is not permitted by statutory regulation or exceeds the permitted use, you will need to obtain permission directly from the copyright holder. To view a copy of this licence, visit http://creativecommons.org/licenses/by/4.0/. The Creative Commons Public Domain Dedication waiver (http://creativeco mmons.org/publicdomain/zero/1.0/) applies to the data made available in this article, unless otherwise stated in a credit line to the data. 
Keywords: Regulatory B lymphocytes, Antigen-presenting cells, Chemokine receptors, Neuroinflammation, Experimental autoimmune encephalomyelitis, Central nervous system homing

\section{Background}

Dopamine has emerged as a major regulator of inflammation by stimulating dopamine receptors (DRs) in innate and adaptive immune cells $[1,2]$. Remarkably, the stimulation of low-affinity DRs, including DRD1 and DRD2, by high levels of dopamine has been shown to exert anti-inflammatory effects in sepsis [3], Parkinson's disease $[4,5]$, inflammatory bowel diseases $[6,7]$, and multiple sclerosis (MS) $[8,9]$. Conversely, low dopamine levels, through the stimulation of highaffinity DRs, including DRD3, DRD4 and DRD5, have been shown to promote inflammation in animal models of Parkinson's disease [10-13], inflammatory bowel diseases [14, 15], allergic asthma [16], and MS [17-20]. Interestingly, alterations in dopamine levels have been detected in the striatum in experimental autoimmune encephalomyelitis (EAE) [21-23]. Moreover, the dopaminergic system has been found to be altered in both innate and adaptive immune system in MS patients $[19,24,25]$. Since the reduction of striatal dopamine has been shown to induce an earlier onset of the disease and to increase EAE severity [22], it is likely that dopaminergic signalling through high-affinity DRs in immune cells infiltrating the brain might play a regulatory role in central nervous system (CNS) autoimmunity. According to this possibility, previous studies have addressed the role of DRD5 in dendritic cells (DCs) and $\mathrm{CD} 4^{+} \mathrm{T}$ cells. DRD5-signalling in DCs potentiated IL-12 and IL-23 production, thereby promoting Th1 and Th17-mediated autoimmunity in the CNS [17-19]. In addition, DRD5-signalling in $\mathrm{CD} 4^{+} \mathrm{T}$ cells exerted a dual role in the physiopathology of EAE, potentiating early inflammation mediated by effector $\mathrm{T}$ cells, but exacerbating suppressive activity in Treg cells and thereby dampening disease manifestation in late EAE stages [20]. Although dopaminergic signalling through DRD3, which displays the highest affinity for dopamine, has been strongly associated with the development and progression of inflammatory disorders $[10,12,14,15$, 26], the involvement of this receptor in the physiopathology of MS/EAE remains poorly explored.

MS is a chronic inflammatory disorder involving an autoimmune response to the CNS characterized by demyelination, axonal degeneration, and gliosis [27, 28]. Several studies have consistently shown a major role of $\mathrm{CD}^{+} \mathrm{T}$ cells leading the damage of the CNS, whereas the involvement of $\mathrm{B}$ cells in the pathogenesis of MS was attributed for many years just to autoantibody production [29]. Nevertheless, current successful therapeutic approaches based on B-cell depletion have motivated investigations to improve our understanding of the role of B cells in the pathophysiology of MS [30-33]. Accordingly, the evidence has suggested that, in addition to the production of autoantibodies, B cells might play an essential role in triggering the autoimmune response as well as in the progression and recovery of the disease in animal models of MS [34-38]. Some studies performed in mice have indicated that B cells play an important role as antigen-presenting cells (APC) in the CNS, which is required for the re-stimulation of autoreactive $\mathrm{T}$ cells infiltrating the target tissue [37-40]. Moreover, another group of studies has shown that $B$ cells participate as potent regulators of inflammation, providing both pro-inflammatory or immunosuppressive cytokines [34, 35, 38, 41, 42]. Notably, the production of regulatory cytokines by $\mathrm{B}$ cells might be induced by the recognition of autoantigens or by mechanisms independent of Ag-recognition.

The main animal model to study MS is the EAE, for which there are many variants. Two different EAE variants have been used to study different features of B cells in MS, which differ in the nature of the autoantigen [43, 44]. The first one is induced by immunization with a short peptide derived from the myelin oligodendrocyte glycoprotein $\left(\mathrm{MOG}_{35-55} ; \mathrm{pMOG}\right)$. In this model, B cells may be activated independently of the B-cell receptor (BCR) specificity. Although in the pMOG-induced EAE model $B$ cells are capable of presenting short peptides through direct binding to cell surface MHC-II molecules, their function is of secondary relevance as EAE develops with the same kinetic and intensity in wild-type mice and B-cell deficient mice [38]. Of note, the early depletion of B cells with an anti-CD20 antibody results in exacerbated disease manifestation, whilst the late treatment with anti-CD20 antibody reduces the disease severity in pMOG-induced EAE in C57BL/6 mice, indicating that $B$ cells play an important regulatory role in this EAE model in this mouse strain [35]. Furthermore, these results indicate that despite APC-function of B cells is negligible in this EAE model, B cells still play a regulatory role, immunosuppressive at early-stage and pro-inflammatory at late-stage [35]. The second EAE model is induced by immunization with the full-length human MOG protein (huMOG), in which antigen-specific activated B cells play a primary role in the development of the disease, exerting a fundamental APCs function in the CNS, and also 
provide significant pro-inflammatory cytokines and participate as a source of antibody-producing plasma cells [38, 45-47].

Despite B cells play an important role in the physiopathology of MS [33] and constitute one of the leukocyte populations with the highest levels of DRs expression [48], the role of dopaminergic stimulation in B cells in CNS autoimmunity has not been yet studied. Indeed, $B$ cells have been shown to express the highest levels of DRD3 [11, 48], whose stimulation has been strongly associated with inflammation [49]. Here we addressed the role of DRD3 in the adaptive immune system in CNS autoimmunity. Our findings indicate that DRD3-expression in $\mathrm{CD} 4^{+} \mathrm{T}$ cells was irrelevant in EAE, whilst DRD3 in $\mathrm{B}$ cells exerted fundamental regulatory processes in CNS autoimmunity. Mechanistic analysis revealed a dual role of DRD3 in B cells, promoting CNS-tropism of B cells with APC potential and favouring the infiltration of regulatory (suppressive) B cells into the CNS.

\section{Methods}

\section{Animals}

Six- to eight-week-old male or female mice of the C57BL/6 background were used in all experiments. Wildtype (WT, $D r d 3^{+/+}$), $\mu \mathrm{MT}$ (B-cell deficient), $R a g 1^{-/-}$(Band T-cell deficient) and 2D2 (bearing the transgenic TCR specific for the $\mathrm{MOG}_{35-55}$ peptide on $\mathrm{IA}^{\mathrm{b}}$ molecules; $\mathrm{TCR}^{\mathrm{MOG}}$ ) mice were purchased from The Jackson Laboratory (Bar Harbor, ME). DRD3-knockout $\left(\operatorname{Drd3}^{-/-}\right)$ mice were kindly donated by Dr. Marc Caron [50] and B6.SJL.PTPRC $\left(C d 45.1^{+/+}, \mathrm{Drd}^{+/+}\right)$mice were kindly donated by Dr. Maria Rosa Bono [51]. Transgenic 2D2 $\mathrm{Drd} 3^{-/-}$mice were generated by crossing parental mouse strains.

\section{Generation of mixed-bone marrow chimera mice}

Mice harbouring Drd3 deficiency in specific cell populations were generated using the mixed-bone marrow (BM) chimera system, as described previously [34, 41]. Briefly, $\mathrm{Rag1}^{-1-}$ or $\mathrm{\mu MT}$ mice were irradiated with $1100 \mathrm{cGy}$ $\gamma$-irradiation (Cs source), and $24 \mathrm{~h}$ later received the i.v. transfer of a mix of donor BM cells from indicated mouse strains $\left(10^{7}\right.$ total BM cells per recipient mouse). Female $\mathrm{BM}$ was used to transfer into male or female recipients, whilst male BM was used to transfer just into male recipients (to avoid incompatibility of Y-encoded genes by female recipients). Before EAE experiments, chimeric mice were left untreated for 8 weeks to let the hematopoietic system reconstitute the peripheral lymphoid system, as described before [20]. To restrict the genetic Drd3 deficiency to B and T cells, irradiated $\mathrm{Ragl}^{-/-}$ mice received a BM mix composed of $80 \%$ from $\mathrm{Rag1}^{-/-}$ mice and 20\% from $\mathrm{Drd3}^{-/-}$mice. The control group received a BM mix composed of $80 \%$ from $\operatorname{Rag1^{-/-}}$ mice and $20 \%$ from $D r d 3^{+/+}$mice. Thus, all B and T cells were originated from the $D r d 3^{-/-}$(or $D r d 3^{+/+}$in the control group) BM. On the other hand, the 5:1 ratio $\left(\operatorname{Rag}^{-1}{ }^{-}\right.$-to$\mathrm{Drd3}^{-/-}$or $\mathrm{Rag1}^{-/-}$-to-Drd3 ${ }^{+/+}$) in the donor BM [52] ensure that all the other hematopoietic lineages different from lymphocytes were predominantly originated from the $\operatorname{Rag} 1^{-1-} \mathrm{BM}$, and therefore were $\operatorname{Drd} 3$ sufficient. To restrict genetic $D r d 3$ deficiency only to B cells, irradiated $\mu \mathrm{MT}$ mice received a BM mix composed of $80 \%$ from $\mu \mathrm{MT}$ mice and 20\% from $\mathrm{Drd} 3^{-/-}$mice. The control group received a BM mix composed of $80 \%$ from $\mu \mathrm{MT}$ mice and $20 \%$ from $D r d 3^{+/+}$mice. Thus, all B cells were originated from the $\mathrm{Drd3}^{-/-}$(or $\mathrm{Drd3}^{+/+}$in the control group) $\mathrm{BM}$, whilst all the other hematopoietic lineages were predominantly originated from the $\mu \mathrm{MT}$ BM. FACS analysis confirmed hematopoietic reconstitution of sublethally irradiated mice. In some experiments, mixed BM chimera mice were generated by reconstituting irradiated $\mu \mathrm{MT}$ mice with a BM mix from B6.SJL.PTPRC $\operatorname{Drd}^{+/+}\left(C d 45.1^{+/+}\right)$mice and BM from $D r d 3^{-/-}$mice $\left(C d 45.2^{+/+}\right)$at 50 -to- 50 or 30 -to-70 ratios.

\section{EAE induction and evaluation}

Experimental groups were generated by selecting mice at random while maintaining the same proportions of males and females and pairings by age. Mice displaying dwarfism and/or malformations were excluded. Experimental mice were s.c. immunized with $50 \mu \mathrm{g}$ myelin oligodendrocyte glycoprotein $35-55$ peptide $\left(\mathrm{pMOG}_{35-55}\right.$; Genetel Laboratories, Madison, WI) or $100 \mu \mathrm{g}$ human MOG protein (huMOG; Anaspec) emulsified in CFA (Invitrogen) supplemented with heat-inactivated Mycobacterium tuberculosis H37 RA (Difco Laboratories, Detroit, MI). In addition, mice received the i.p. administration of $500 \mathrm{ng}$ pertussis toxin (Calbiochem, La Jolla, CA) on days 0 and 2. In primary-progressive EAE experiments, $24 \mathrm{~h}$ before disease induction $\mathrm{Rag1}^{-/-}$mice received the i.v. transfer of $7,5 \times 10^{5}$ splenic naïve $\left(\mathrm{CD} 25^{-} \mathrm{CD} 44^{-} \mathrm{CD} 62 \mathrm{~L}^{+}\right) \mathrm{CD} 4^{+}$ $\mathrm{T}$ cells purified from $\mathrm{Drd3} 3^{+/+}$or $\mathrm{Drd3} 3^{-/-} 2 \mathrm{D} 2$ transgenic mice. The clinical manifestation was assessed daily according to the following scoring criteria: 0 , no detectable signs; 1 , flaccid tail; 2 , hind limb weakness or abnormal gait; 3, complete hind limb paralysis; 4, paralysis of fore and hind limbs; and 5, moribund or death.

The animals were included in the study when they underwent successful pMOG-CFA or huMOG-CFA immunization, defined by the formation of a sub-cutaneous emulsion at the site of injection. The animals were excluded: (i) when leakage of the emulsion was observed during injection; (ii) when infections or diseases unrelated to the experiment were detected, or when the 
animal died prematurely (usually less than $0.5 \%$ of the animals), avoiding the collection of disease severity data.

For the isolation of CNS mononuclear cells, mice were perfused through the left cardiac ventricle with cold PBS. The brain and spinal cord were dissected, and CNS tissue was minced into small pieces and digested by collagenase D $(2.5 \mathrm{mg} / \mathrm{ml}$; Roche Diagnostics) and DNase I $(1 \mathrm{mg} / \mathrm{ml}$; Sigma) at $37{ }^{\circ} \mathrm{C}$ for $45 \mathrm{~min}$. Digested tissue was filtered through a $70 \mu \mathrm{m}$ cell strainer obtaining single cell suspension that was subjected to centrifugation in a Percoll gradient $(70 \% / 30 \%)$. Mononuclear cells were removed from the interphase and resuspended in culture medium for further analysis. No blind protocol was carried out.

\section{Antibodies and flow cytometry analysis}

For all analyses, live/dead discrimination was assessed using Zombie Aqua (ZAq) Fixable Viability kit (Biolegend). Spleens were minced until reach a cell suspension and then red blood cells were lysed using ammoniumchloride-potassium (ACK) buffer. Fluorochrome-conjugated mAb specific to mouse CD45 (clone 30-F11), CD19 (clone 6D5), IgD (clone 11-26c.2a), IgM (clone RRM-1), IL-6 (clone MP5-20F3), IL-10 (clone JES5-16E3), CXCR3 (clone CXCR3-A3), CD49d (clone R1-2), Tbet (clone 4B10), CD4 (clone GK-1.5), IFNY (clone XMG1.2), IL-17 (clone TC11-18H10.1), GM-CSF (clone MP1-22E), CD20 (clone SA275A11), MHC-II (clone M5/114.15.2), CD21/ CD35 (clone 7E9), CD1d (clone 1B1), CD5 (clone 53-73), CD23 (clone B3B4), CD138 (clone 281-2), CD44 (clone IM7), TCR $\beta$ (clone B183983), CD11c (clone N418), CD3 (clone 145-2C11), CD8 (clone 58-6,7), CD11b (clone M1/70), F4/80 (clone BM8), Ly6G (clone 1A8), CD45.1 (clone A20) and CD45.2 (clone 104) were purchased from Biolegend and to mouse Foxp3 (clone FJK-16 s) from eBioscience.

For the immunostaining of DRD2, DRD3, and DRD5, the rabbit anti-DRD2 antibody (ADR-002, Alomone labs), the rabbit anti-DRD3 antibody (ADR-003, Alomone labs), or the rabbit anti-DRD5 antibody (ADR005, Alomone labs) was directly used or pre-incubated, respectively, with the antigenic peptide DRD2 ${ }_{11-26}$ (DDLERQNWSRPFNGSE), with the antigenic peptide DRD3 $_{15-29}$ (CGAENSTGVNRARPH) or with the antigenic peptide DRD5 ${ }_{199-211}$ (EEGWELEGRTENC) used to develop the antibodies (in a mixture of $0.8 \mathrm{mg} / \mathrm{ml}$ antibody and $0.4 \mathrm{mg} / \mathrm{ml}$ peptide) for $30 \mathrm{~min}$ as a control to abolish the specific immunostaining. For tyrosine hydroxylase $(\mathrm{TH})$ immunostaining, the rabbit IgG antiTH antibody (Santa Cruz Biotechnology; sc-14007) was used as primary antibody and compared with the rabbit irrelevant IgG (Santa Cruz Biotechnology; sc-3888) immunostaining as a negative control. Secondary goat anti-rabbit IgG-PE (50-8036) was obtained from TONBO Biosciences.

For intracellular immunostaining, cells were first labelled with antibodies specific for cell surface markers and then fixed and permeabilized with Foxp3 Fixation/Permeabilization kit (eBioscience). Next, Foxp3, Tbet, or $\mathrm{TH}$ immunostaining or intracellular cytokine immunostaining was performed in permeabilized cells followed by flow cytometry analysis. For analysis of cytokine production, cells were re-stimulated with ionomycin (Sigma) and PMA (Sigma) in the presence of brefeldin A (Invitrogen) for $5 \mathrm{~h}$ before immunostaining. All immunostainings were performed for $30 \mathrm{~min}$ at $4{ }^{\circ} \mathrm{C}$. To quantify the absolute number of cells, $50 \mu \mathrm{L}$ of 123 count eBeads (Thermo Fisher Scientific) was added to each sample prior to analysis by flow cytometry, and cell concentration was calculated using the following formula:

$$
\begin{aligned}
& \text { Cellconcentration }(\text { cells } / \mathrm{mL}) \\
& =\frac{\text { Cellcount } \times \text { eBeadvolume }}{\text { eBeadcount } \times \text { cellvolume }} \times \text { eBeadconcentration. }
\end{aligned}
$$

Data were collected with a FACSCanto II (BD) and results were analysed with FACSDiva (BD) and FlowJo software (Tree Star).

\section{In vitro B-cell culture}

Splenic naïve B cells $\left(\mathrm{TCR} \beta^{-} \mathrm{CD} 11 \mathrm{c}^{-} \mathrm{CD} 19^{+} \operatorname{IgD}^{\text {hi }} \operatorname{IgM}^{\text {int }}\right)$ were isolated by cell-sorting from $\mathrm{Drd3}^{+/+}$or $\mathrm{Drd3^{-/ }}$ mice. When proliferation was determined, naïve $B$ cells were loaded with $5 \mu \mathrm{M}$ Cell trace violet (CTV; Invitrogen, Carlsbad, CA, USA) before stimulation. Cells were stimulated with $10 \mu \mathrm{g} / \mathrm{mL}$ of goat anti-mouse IgM F(ab)' fragments (eBioscience); $1 \mu \mathrm{g} / \mathrm{mL}$ anti-CD40 (clone 1C10; Biolegend); $1 \mu \mathrm{M}$ CpG DNA (ODN 1824; InvivoGen) and $10 \mathrm{ng} / \mathrm{mL}$ IFN- $\gamma$ (Peprotech) for $5 \mathrm{~d}$. Then, CXCR3, CD49d, Tbet expression, or cytokine production were determined by flow cytometry analysis. The extent of cell death was quantified using the ZAq Fixable Viability kit (Biolegend).

\section{In vitro antigen-presentation assays}

huMOG protein or $\mathrm{pMOG}_{35-55}$ were coupled to glutaraldehyde-activated amino beads $\left(40 \times 10^{6}\right.$ beads for $20 \mu \mathrm{g}$ huMOG or pMOG) together with $\mathrm{F}\left(\mathrm{ab}^{\prime}\right) 2$ anti-mouse-IgM fragments in equal concentrations, as previously described [53]. Splenic CD19 ${ }^{+}$B cells were sorted from $\mathrm{Drd3} 3^{+/+}$or $\mathrm{Drd3} 3^{-/-}$animals and then incubated with huMOG- or $\mathrm{pMOG}_{35-55^{-} \text {-coated beads }}$ in a B-cell-to-bead ratio $1: 1$ for $5 \mathrm{~h}$ at $37^{\circ} \mathrm{C}$ to allow the uptake and processing of antigens. Next, B cells were washed and then incubated with MOG-specific CD4 ${ }^{+}$ $\mathrm{T}$ cells at $\mathrm{B}$-cell to $\mathrm{T}$-cell ratio 1:5 for 5 days. For each 
point, $10^{5} \mathrm{CD}^{+} 2 \mathrm{D} 2 \mathrm{~T}$ cells loaded with CTV were used. The proliferation and production of cytokines were evaluated by FACS analysis.

\section{Real-time quantitative PCR}

Total RNA was extracted from cells using the TotalRNA EZNA kit (Omega Bio-Tek). The RNA was DNasedigested using the TURBO DNA-free kit (Ambion) and then used to synthesize cDNA catalysed by the M-MLV reverse transcriptase (Life Technologies). Quantitative gene-expression analysis was performed using Brilliant II SYBR Green QPCR Master Mix (Agilent). Expression of target genes was normalized to the levels of gapdh transcripts and multiplied by an arbitrary factor. il 10 Forward 5'-GAA GAC AAT AAC TGC ACC CA-3'; illo Reverse 5'-CAA CCC AAG TAA CCC TTA AAG TC-3'; il6 Forward 5'-AGG ATA CCA CTC CCA ACA GAC CT-3'; il6 Reverse 5'-CAA GTG CAT CGT TGT TCA TAC3'; csf2 Forward 5'-ACC ACC GCG GAT TTC AT-3'; csf2 Reverse 5-TCA TTA CGC AGG CAC AAA AG-3'; gapdh Forward 5'-TCC GTG TTC CTA CCC CCA ATG3'; gapdh Reverse 5'-GAG TGG GAG TTG CTG TTG AAG-3'.

\section{CD19 immunofluorescence analysis}

Mice were perfused through the left cardiac ventricle with cold PBS, and then the brain was removed from the skull of each mouse. Then the brains were fixed with $4 \%$ paraformaldehyde for $48 \mathrm{~h}$ at $4{ }^{\circ} \mathrm{C}$. Next, the tissues were dehydrated by immersion in 30\% sucrose for $48 \mathrm{~h}$ at $4{ }^{\circ} \mathrm{C}$. Then brains were embedded in optimal cutting temperature (OCT) compound and sagittally cut in $12 \mu \mathrm{m}$ thick sections. Brain sections were mounted in glass-treated slides $76 \times 26 \mathrm{~mm}($ StarFrost $\odot)$ and dried at $50{ }^{\circ} \mathrm{C}$ for $10 \mathrm{~h}$. Then brain slices were hydrated with PBS, and epitope exposition was achieved by treatment with citrate buffer $(\mathrm{pH} 6.0)$ at $90{ }^{\circ} \mathrm{C}$ for $1 \mathrm{~min}$. Afterwards, brain slices were washed three times with PBS for $5 \mathrm{~min}$ each, and then the slices were blocked and permeabilized with blocking solution (PBS containing 0.3\% Triton and $5 \% \mathrm{BSA}$ ) for $1 \mathrm{~h}$ at room temperature. The brain slices were then incubated with anti-mouse CD19 conjugated to allophycocyanin (Thermo Fisher Scientific, CAT\# 17-0193-82) diluted at 1:200 in blocking solution and co-incubated with Hoechst nuclear staining for $10 \mathrm{~h}$ at $4{ }^{\circ} \mathrm{C}$. Next, the slices were washed three times with PBS in agitation for $10 \mathrm{~min}$ each. Finally, the brain slices were washed with distilled water and then mounted with Fluoromount mounting medium with glass coverslips. Images were acquired in an epifluorescence microscope at $10 \times$ and $20 \times$ objectives and analysed with the Fiji software.

\section{Statistical analyses and sample size estimation}

The sample size was estimated with the mean and dispersion obtained from preliminary data using the sample size calculator: https://www.stat.ubc.ca/ rollin/stats/ ssize $/ \mathrm{n} 2 . \mathrm{html}$. A power of $80 \%$ was assumed. Using the same sample size calculator, post hoc analysis confirmed that all data have a power $\geq 75 \%$. All values are expressed as the mean \pm SEM. Statistical analysis was performed with two-tailed unpaired Student's $t$-test when comparing only two groups and with one-way ANOVA followed by Tukey's post hoc test when comparing more than two groups with only one variable (treatment or genotype). To analyse differences in experiments comparing different genotypes and different treatments, two-way ANOVA followed by Sidak's post hoc test was performed. All analyses were carried out using the GraphPad Prism 6 Software. P values $<0.05$ were considered significant.

\section{Results \\ DRD3-stimulation in the adaptive immune system is required to the development of CNS autoimmunity}

To address the role of DRD3 in the adaptive immune system in the development of CNS autoimmunity we generated chimeric mice bearing Drd3-deficient adaptive immune system and $D r d 3$-sufficient innate immune system. For this purpose, recombination-activating gene 1 knockout $\left(\mathrm{Rag1}^{-{ }^{-}}\right)$mice, which are devoid of $\mathrm{T}$ and B lymphocytes, were $\gamma$-irradiated with a myeloablative dose and then received the transfer of donor bone marrow (BM) obtained from $\operatorname{Rag} 1^{-/-}$mice and $\operatorname{Drd3}^{-/-}$mice mixed in a 5:1 ratio $R a g 1^{-/-}$-to-Drd $3^{-/}$as described before [34]. Thus, after BM reconstitution, Drd3 deficiency was confined to T and B lymphocytes, whilst nonlymphocytic hematopoietic cells were mostly originated from Drd3-sufficient $\left(\mathrm{Ragl}^{-/-}\right)$BM. The control group of mice, harbouring Drd3-sufficient adaptive immune system, received the transfer of BM obtained from Rag1 $1^{-1-}$ mice $(80 \%)$ and $D r d 3^{+/+}$mice (20\%). Eight weeks after $\mathrm{BM}$-transfer, EAE was induced, and the extent of disease severity was evaluated throughout the time-course of disease development. The results show that EAE manifestation was abrogated in mice bearing Drd3-deficient adaptive immune system (Fig. 1A), indicating that DRD3 in $\mathrm{T}$ and/or B lymphocytes was required for EAE development. No differences were observed between males and females from the same experimental groups. Of note, DRD3-signalling in $\mathrm{CD} 4^{+} \mathrm{T}$ cells has been shown to promote inflammation in animal models of Parkinson's disease [10-12] and inflammatory bowel diseases [14, 15]. Accordingly, we next evaluated the role of DRD3 in autoreactive $\mathrm{CD}_{4}^{+} \mathrm{T}$ cells in a mouse model of primaryprogressive MS. To this end, $24 \mathrm{~h}$ before EAE induction, 


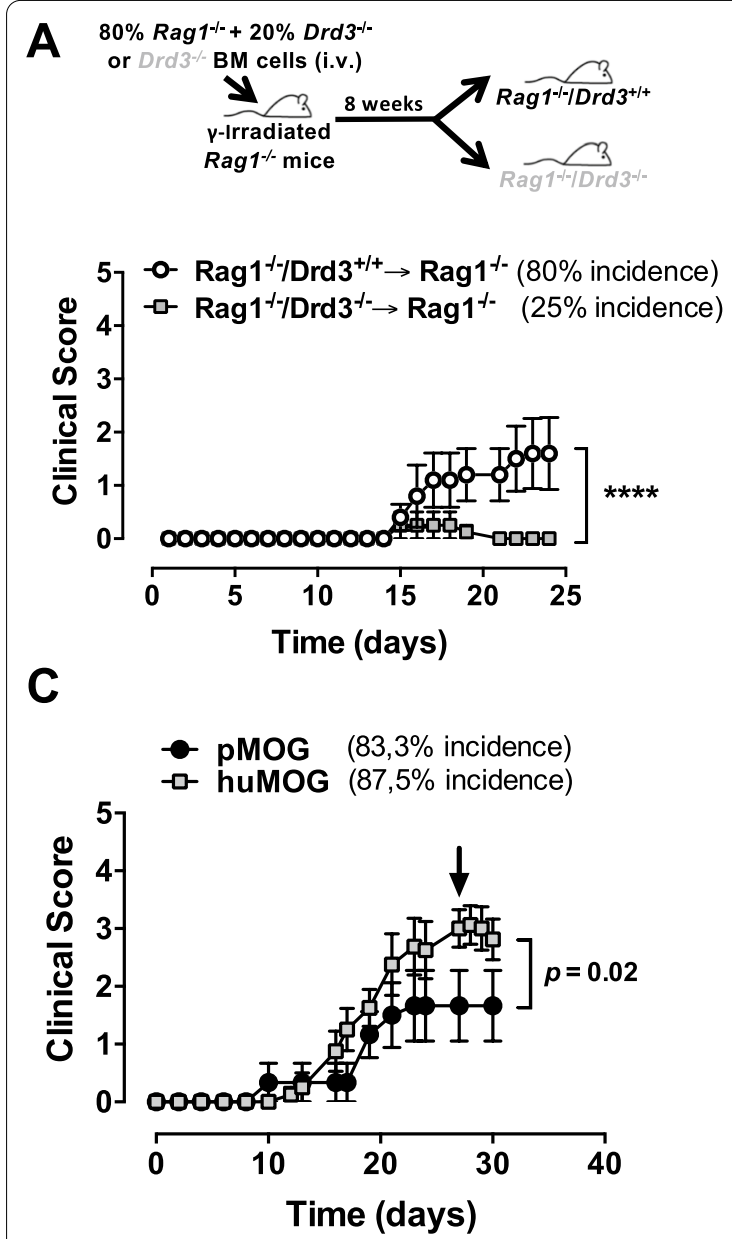

B
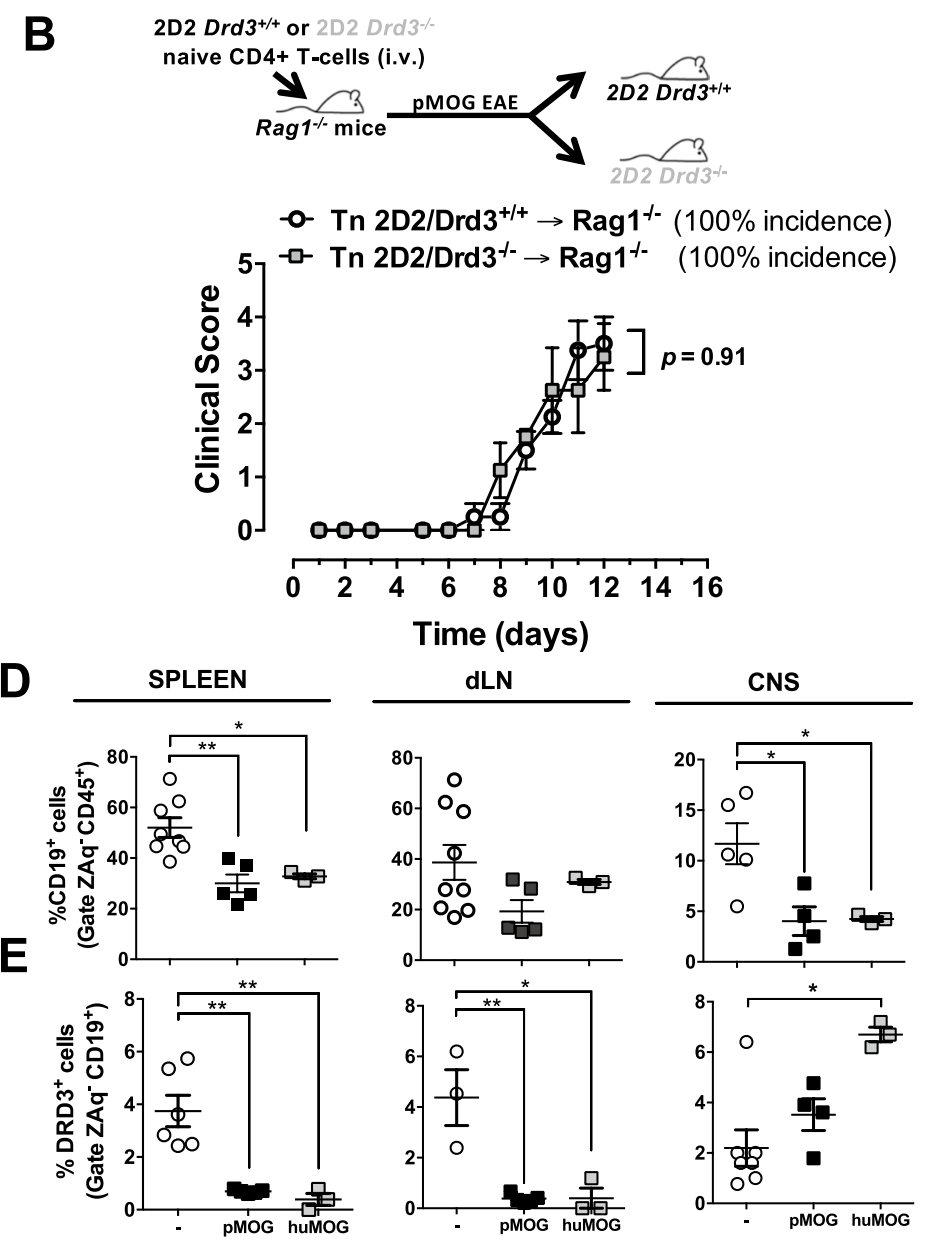

Fig. 1 DRD3-signalling in lymphocytes is required for the development of CNS autoimmunity. A BM chimeric mice harbouring Drd3-deficient or Drd3-sufficient lymphocytes were generated by the i.v. transfer of a 4:1 mixed BM from Rag $1^{-/-}$and Drd3 ${ }^{-/-}$mice (grey symbols) or 4:1 mixed BM from Rag ${ }^{-/-}$and Drd3 ${ }^{+/+}$mice (white symbols), respectively, into $\gamma^{-i r r a d i a t e d ~ R a g 1^{-/-}}$recipient mice. Afterwards, EAE was induced in chimeric mice by immunization with $\mathrm{pMOG}_{35-55}$ in CFA followed by pertussis toxin injection and disease severity was determined throughout the time-course of the disease development. $n=4-5$ mice per group. Top panel shows an illustration of the experimental strategy for generation of chimeric mice. Bottom panel shows the quantification of clinical score for different experimental groups. (B) Primary progressive EAE was induced in mice bearing Drd3-deficient (grey symbols) or Drd3-sufficient (white symbols) CD4 ${ }^{+} T$ cells by the i.v. transfer of transgenic naive $\mathrm{CD}^{+} \mathrm{T}$ cells $\left(\mathrm{Tn} ; 7.5 \times 10^{5}\right.$ cells per mouse) isolated from $\mathrm{Drd3}^{-/-} 2 \mathrm{D} 2$ or $\mathrm{Drd3}^{+/+} 2 \mathrm{D} 2$ mice into $\mathrm{Rag}^{-/-}$recipient mice. Disease severity was determined throughout the time-course of the disease development. $n=4$ mice per group. Top panel illustrates the experimental design to induce primary-progressive EAE. Bottom panel shows the quantification of clinical score for different experimental groups. C EAE was induced in wild-type C57BL/6 mice by immunization with PMOG $_{35-55}$ (black symbols) or huMOG (grey symbols) in CFA followed by pertussis toxin injection. Disease severity was evaluated throughout the time-course of the disease development. $n=6-8$ mice per group. D, E At the peak of disease severity (indicated by an arrow in C), mononuclear cells were isolated from the spleen, draining lymph nodes (dLN) and central nervous system (CNS) and the frequency of $\mathrm{CD} 19^{+} \mathrm{B}$ cells from the $\mathrm{CD} 45^{+}$gate $(\mathbf{D})$ and the percentage of DRD3 expression in $\mathrm{CD} 19^{+} \mathrm{B}$ cells $(\mathbf{E})$ were evaluated. A control group (white symbols) without immunization (-) was included in the analysis. D, E $n=3-9$ mice per group. A-E Each symbol represents data obtained from an individual mouse. The mean \pm SEM are depicted. ${ }^{*}, p<0.05 ;{ }^{* *}, p<0.01 ;{ }^{* * *}, p<0.0001$ by Mann-Whitney $U$ test $(\mathbf{A}-\mathbf{C})$ or one-way ANOVA followed by Tukey's post hoc $t$-test (D, E)

Rag1 $1^{-/-}$mice received the transfer of naïve $\mathrm{CD} 4^{+} \mathrm{T}$ cells isolated from Drd3-deficient or Drd3-sufficient 2D2 transgenic mice, which express a transgenic TCR specific for the $\mathrm{MOG}_{35-55}$ peptide (pMOG) on IA ${ }^{\mathrm{b}}$ molecules [54]. The results show that mice receiving $\operatorname{Drd3}$-deficient or Drd3-sufficient $\mathrm{CD} 4^{+} \mathrm{T}$ cells developed EAE with similar kinetics and severity (Fig. 1B), thus ruling out a relevant role of DRD3 in $\mathrm{CD}^{+}{ }^{+} \mathrm{T}$ cells in the development of CNS autoimmunity. No differences were observed between males and females from the same experimental groups. We next attempted to determine the role of DRD3 in B cells, which have been associated with the production 
of pro-inflammatory and anti-inflammatory cytokines in EAE [35] and have been involved as key APC in the development of CNS autoimmunity [38]. Of note, our immunofluorescence analysis of $\mathrm{CD} 19^{+}$cells in brain slices shows that the extent of B-cell infiltration into the CNS significantly correlates with the clinical EAE score (Additional file 1: Fig. S1). Accordingly, to analyse the protective and pathogenic potential DRD3-signalling in B cells in CNS autoimmunity, we used two EAE models, which differ in the nature of the autoantigen and display differential B-cell involvement: (i) the EAE model independent of the APC-function of B cells, which is induced by immunization with pMOG; and (ii) the EAE model dependent of the APC-function of B cells, which is induced by immunization with huMOG. In this regard, we first compared the time-course of clinical manifestation, and the extent of DRD3 expression and B-cell frequency in relevant tissues when EAE was induced by immunization of WT mice with PMOG or huMOG. The results show that EAE manifestation was similar in both models, although the peak of severity was higher in huMOG-induced EAE than pMOG-induced EAE (Fig. 1C). No differences were observed between males and females from the same experimental groups. In addition, in both models, B-cell frequency was significantly reduced in the spleen and the CNS, whereas it remained unchanged in the cervical lymph nodes (CNS draining lymph nodes; dLN) during the peak of disease manifestation (Fig. 1D). Interestingly, the frequency of DRD3-expression was selectively increased in B cells infiltrating the CNS upon huMOG-induced EAE but not upon pMOG-induced EAE (Fig. 1E). Conversely, the percentage of DRD3 expression was reduced to a similar extent in dLN and splenic B cells in both EAE models (Fig. 1E; see the gating strategy for the analysis of DRD3 expression in Additional file 1: Fig. S2A). Interestingly, the density of DRD3 expression in B cells infiltrating the CNS was selectively reduced upon pMOG-induced but not in huMOG-induced EAE (Additional file 1: Fig. S2B, C). Nonetheless, the density of DRD3 expression was reduced in those $\mathrm{B}$ cells circulating through peripheral blood and the spleen upon both pMOG-induced or huMOG-induced EAE (Additional file 1: Fig. S2B, C). Further analysis of DRD3-expression in different B-cell subsets indicated that DRD3 upregulation observed in $B$ cells infiltrating the CNS upon huMOG-EAE occurred selectively in $\mathrm{CD} 20^{+} \mathrm{MHC}^{-\mathrm{II}^{+}} \mathrm{B}$ cells (Additional file 1: Fig. S3), which display APC-function [38]. In addition to $\mathrm{CD} 20^{+}$MHC- $\mathrm{II}^{+} \mathrm{B}$ cells, we found that $\mathrm{CD} 21^{+} \mathrm{CD} 23^{+}$ $\mathrm{IgM}^{+} \mathrm{B}$ cells, which have been described to exert suppressive function [55], was the only B-cell subset expressing detectable levels of DRD3 upon pMOG-induced EAE in the CNS and dLN (Additional file 1: Fig. S3B-D).
Taken together, these results suggest that DRD3 in B cells plays an important role in the development of CNS autoimmunity, involving different B-cell subsets depending on the nature of the antigen.

\section{Drd3 deficiency in B cells exacerbates disease severity in an EAE model that does not depend on the APC-function of $B$ cells}

To confirm the relevance of DRD3 in B cells in CNS autoimmunity, we next generated mice harbouring Drd3 deficiency restricted only to B cells. For this purpose, $\mu \mathrm{MT}$ mice, which are devoid of B cells [56], were $\gamma$-irradiated with a myeloablative dose and then received the i.v. transfer of mixed $\mathrm{BM}$ progenitors coming from $\mu \mathrm{MT}(80 \%)$ and $D r d 3^{-/}$or $D r d 3^{+/+}(20 \%)$ mice (Fig. 2A). Since B cells arose from $\operatorname{Drd}^{-1-}$ BM progenitors and all the other cells arose predominantly from $\mu \mathrm{MT}$ BM progenitors in mice bearing $\mu \mathrm{MT} / D r d 3^{-/-}$ $\mathrm{BM}\left(\mu \mathrm{MT} / D r d 3^{-/-} \rightarrow \mu \mathrm{MT}\right.$ mice $)$ after reconstitution of the haematopoietic system, Drd3 deficiency was restricted to B cells in these mice. Conversely, all haematopoietic system was $D r d 3^{+/+}$in control mice bearing $\mu \mathrm{MT} / D r d 3^{-+/+} \mathrm{BM}\left(\mu \mathrm{MT} / D r d 3^{+/+} \rightarrow \mu \mathrm{MT}\right.$ mice $)$ (Fig. 2A). Of note, the frequencies of the main leukocyte populations were equivalent in BM chimera mice containing either $\mathrm{Drd}^{+/+}$or $\mathrm{Drd3}^{-/-}$B cells (Additional file 1: Fig. S4). Using these chimeric mice, we first attempted to determine the relevance of DRD3 in $B$ cells in CNS autoimmunity in a model that does not depend on the APC-function of B cells. Accordingly, EAE was induced with pMOG in $\mu \mathrm{MT} / D r d 3^{-/} \rightarrow \mu \mathrm{MT}$ and $\mu \mathrm{MT} / D r d 3^{+/+} \rightarrow \mu \mathrm{MT}$ mice, and the disease severity as well as the phenotype of $\mathrm{CD}^{+} \mathrm{T}$ cells infiltrating the CNS were determined at the peak of disease manifestation. The results show that EAE severity was significantly higher in $\mu \mathrm{MT} / D r d 3^{-/-} \rightarrow \mu \mathrm{MT}$ mice when compared with control $\mu \mathrm{MT} / \operatorname{Drd}^{+/+} \rightarrow \mu \mathrm{MT}$ mice (Fig. 2B). No differences were observed between males and females from the same experimental groups. According to the exacerbated disease manifestation, $\mu \mathrm{MT} / D r d 3^{-/} \rightarrow \mu \mathrm{MT}$ mice displayed an increased frequency of $\mathrm{CD}^{+}$Tcells producing GM-CSF in the CNS (Fig. 2C, D), which has been described to be the most inflammatory cytokine promoting neuroinflammation in EAE [57]. Conversely, no significant alterations were detected in the phenotype of peripheral $\mathrm{CD} 4^{+} \mathrm{T}$ cells when comparing both experimental groups of mice (Fig. 2E). Interestingly, it has been previously described that B cells express not only the DRD3, but also the DRD2 and DRD5 [48]. Moreover, previous works have shown that some immune cells express the machinery to synthesize dopamine $[1,17,58]$, thus raising the possibility that this neurotransmitter might be released as 


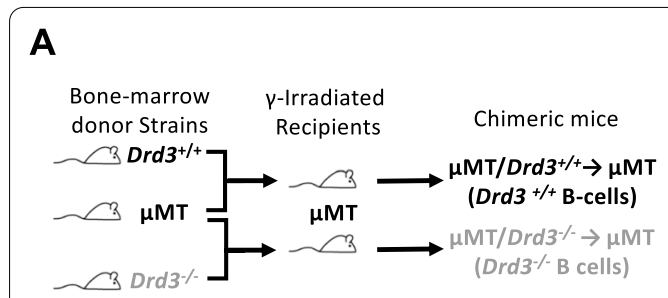

B

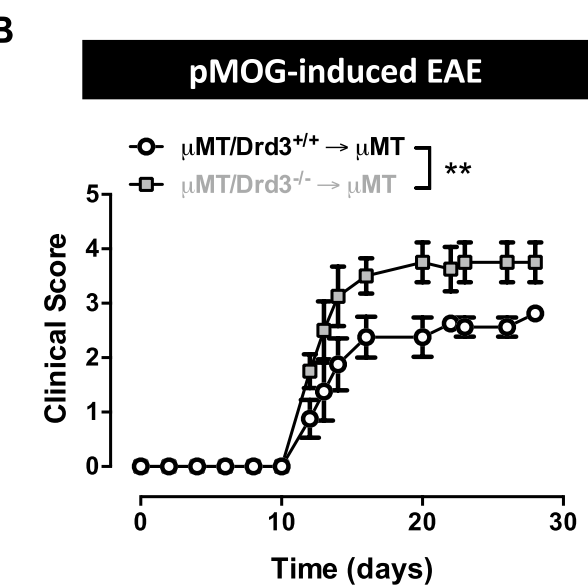

C
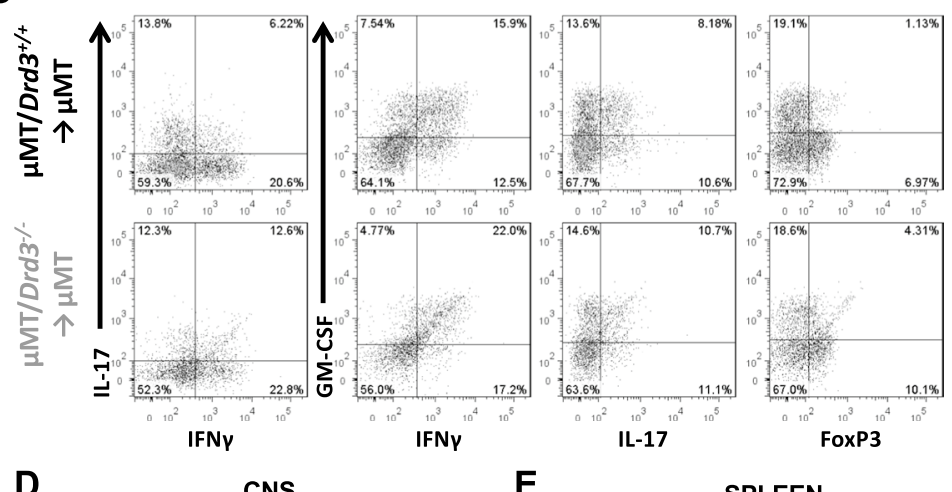

$\mathbf{E}$

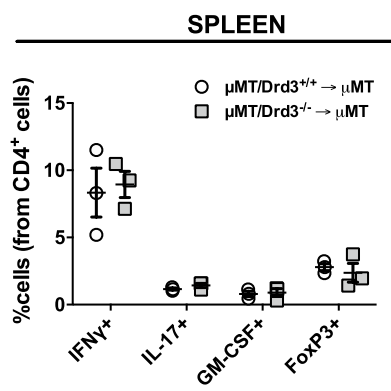

Fig. 2 DRD3-signalling in B cells attenuates disease severity in an EAE model that does not depend on the APC-function of B cells. BM chimeric mice harbouring Drd3-deficient or Drd3-sufficient B cells were generated by the i.v. transfer of a 4:1 mixed BM from $\mu M T$ and Drd3 ${ }^{-1-}$ mice (grey symbols) or 4:1 mixed BM from $\mu \mathrm{MT}$ and $D r d 3^{+/+}$mice (black symbols), respectively, into $\gamma^{-i r r a d i a t e d ~} \mu \mathrm{MT}$ recipient mice. A Schematic illustration of chimeric mice generation. B-E EAE was induced in chimeric mice by immunization with $\mathrm{pMOG}_{35-55}$ in CFA followed by pertussis toxin injection. B Disease severity was evaluated throughout the time-course of the disease development. Values represent the mean $\pm S E M ; n=8$ mice per group. C-E At the peak of disease severity (day 15 post-induction), mononuclear cells were isolated from the CNS (C, D) and the spleen (E) followed by ex vivo stimulation with PMA/ionomycin in the presence of brefeldin A, and intracellular cytokine staining analysis in CD4 ${ }^{+} \mathrm{T}$ cells was carried out by flow cytometry. $\mathbf{C}$ Representative dot-plots in the $\mathrm{CD}^{+}$gate are shown. Numbers indicate the percentage of cells in the corresponding quadrant. D, E Quantification of the frequency of CD4 ${ }^{+} T$ cells producing IFN $\gamma$, IL-17, GM-CSF or expressing FoxP3; $n=3$ mice per group. Each symbol represents data obtained from an individual mouse. The mean \pm SEM are depicted. Data representative from one out of two independent experiments are shown. *, $p<0.05 ;^{* *}, p<0.01$; by Mann-Whitney $U$ test (B) or two-way ANOVA followed by Sidak's post hoc test (D, E)

an immunomodulator. To address the possibility that the effect observed in EAE in those mice harbouring Drd3deficient $B$ cells is due to altered expression of other DRs or to changes in the ability to synthesize dopamine, we compared the expression levels of DRD2, DRD5, and tyrosine hydroxylase (TH) in Drd3-sufficient and Drd3deficient $B$ cells. The results show a similar extent of DRD2 and DRD5 expression in both genotypes (Additional file 1: Fig. S5), thus ruling out the possibility that the effect observed on EAE development in those mice bearing Drd3-deficient B cells is due to altered expression of other DRs. Furthermore, our analysis shows that $\mathrm{TH}$ expression was barely detectable in B cells with both genotypes (Additional file 1: Fig. S5), suggesting that dopamine-derived from $B$ cells does not play a relevant role in the effect observed in EAE in those mice harbouring Drd3-deficient B cells. Thus, these results together indicate that DRD3-signalling in B cells limits the generation of $\mathrm{CD} 4^{+} \mathrm{T}$ cells producing GM-CSF in the CNS and consequently attenuates disease manifestation in a model independent of the APC-function of B cells.

\section{DRD3 in $B$ cell is required for disease manifestation in an EAE model that depends on the APC-function of $B$ cells}

We next evaluated the role of DRD3 in B cells in a model of CNS autoimmunity that depends on the APCfunction of B cells. To this end, EAE was induced in $\mu \mathrm{MT} / D r d 3^{-/-} \rightarrow \mu \mathrm{MT}$ and $\mu \mathrm{MT} / D r d 3^{+/+} \rightarrow \mu \mathrm{MT}$ mice (Fig. 2A) using huMOG and disease severity as well as the extent of T-cell infiltration into the CNS were analysed. Strikingly, Drd3 deficiency in B cells abolished EAE manifestation (Fig. 3A). No differences were observed between males and females from the same experimental groups. According to the absence of disease manifestation in mice harbouring $D r d 3$-deficient B cells, we observed that $\operatorname{Drd} 3$ deficiency resulted in a sharp reduction of the frequency of inflammatory $\mathrm{CD} 4^{+}$Tcells in the 


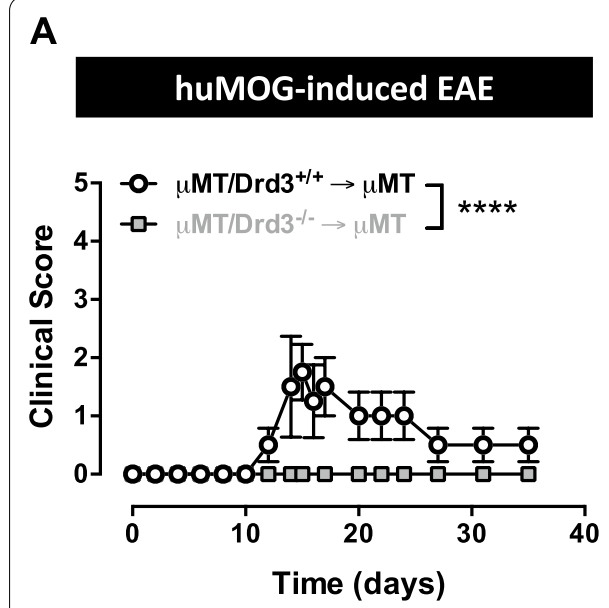

B
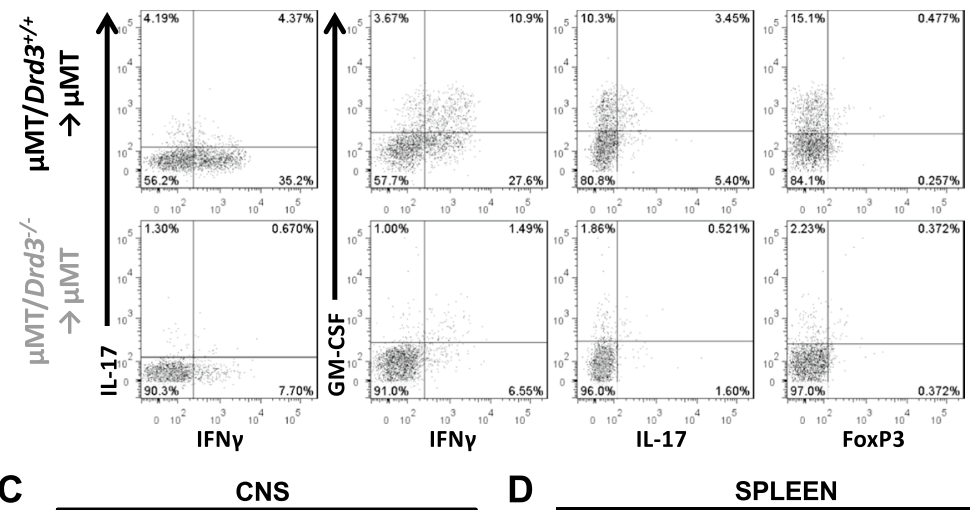

C

D
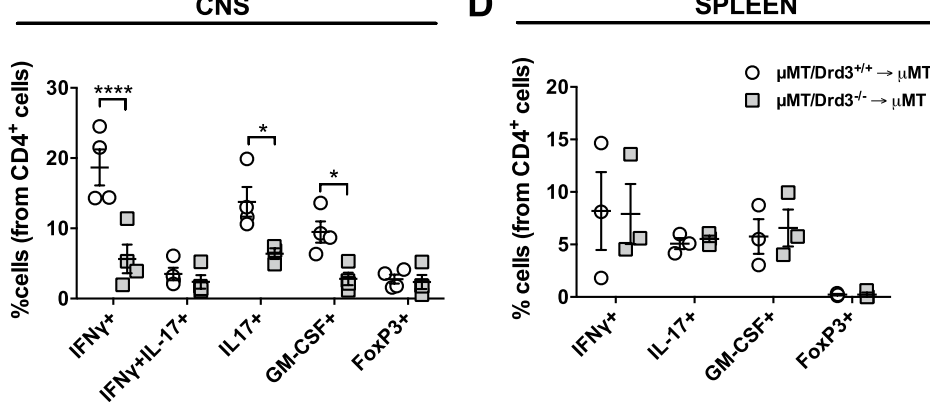

Fig. 3 Drd3 deficiency in B cell abrogates disease manifestation in an EAE model that depends on the APC-function of B cells. BM chimeric mice harbouring Drd3-deficient (grey symbols) or Drd3-sufficient (black symbols) B cells were generated as described in Fig. 2A. Next, EAE was induced in chimeric mice by immunization with huMOG in CFA followed by pertussis toxin injection. A Disease severity was evaluated throughout the time-course of the disease development. Values represent the mean \pm SEM; $n=4$ mice per group. B-D At the peak of disease severity (day 15 post-induction), mononuclear cells were isolated from the CNS (B and $\mathbf{C}$ ) and the spleen (D) followed by ex vivo stimulation with PMA/ionomycin in the presence of brefeldin A, and intracellular cytokine staining analysis in $\mathrm{CD}^{+}{ }^{+}$Tcells was carried out by flow cytometry. B Representative dot-plots in the $\mathrm{CD}^{+}$gate are shown. Numbers indicate the percentage of cells in the corresponding quadrant. C, D Quantification of the frequency of CD4 ${ }^{+}$ T cells producing IFNy, IL-17, GM-CSF or expressing FoxP3. $n=3-4$ mice per group. Each symbol represents data obtained from an individual mouse. The mean \pm SEM are depicted. Data representative from one out of two independent experiments are shown. ${ }^{*}, p<0.05 ;{ }^{* *}, p<0.01 ; *^{* * *}, p<0.0001$ by Mann-Whitney $U$ test $(\mathbf{A})$ or two-way ANOVA followed by Sidak's post hoc test (C, D)

CNS, including Th1, Th17, and GM-CSF producers CD4 $4^{+}$ T cells (Fig. 3B, C). Nevertheless, the frequency of different $\mathrm{CD} 4^{+} \mathrm{T}$-cell subsets in the periphery was not altered by $D r d 3$ deficiency in B cells (Fig. 3D). Taken together these results provide evidence that DRD3 in B cells plays a pro-inflammatory role in a model of CNS autoimmunity that depends on the APC-function of B cells, favouring the participation of inflammatory $\mathrm{CD}^{+} \mathrm{T}$ cells in the CNS and, thereby, promoting disease development.

\section{DRD3-signalling favours the expression of a4-integrin and increases the infiltration of immunosuppressive $B$ cells into the CNS in an EAE model that does not depend on the APC-function of B cells}

Next, we attempted to determine the mechanism by which DRD3 in B cells exerts a suppressive effect on the development of CNS autoimmunity in a model independent of the APC-function of B cells. Since Drd3 deficiency in $\mathrm{B}$ cells affected the $\mathrm{T}$-cell response only in the CNS, but not in the spleen (Fig. 2D, E), we addressed the possibility that DRD3-signalling was affecting B-cell migration into the CNS. In this regard, both $\alpha 4$-integrin (CD49d) and the chemokine receptor CXCR3 [59] have been involved in the infiltration of B cells into the CNS upon autoimmunity. Accordingly, EAE was induced with pMOG in $\mu \mathrm{MT} / D r d 3^{-/-} \rightarrow \mu \mathrm{MT}$ and $\mu \mathrm{MT} / D r d 3^{+/+} \rightarrow \mu \mathrm{MT}$ mice, and the extent of $\alpha 4$-integrin and CXCR3 expression was quantified in B cells infiltrating the CNS and the spleen (see the gating strategy in Figure S6). Whereas similar levels of $\alpha 4$-integrin and CXCR3 expression was detected in splenic B cells, a significant and selective reduction in the frequency and density of $\alpha 4$-integrin expression was observed in B cells infiltrating the CNS from $\mu \mathrm{MT} / D r d 3^{-/-} \rightarrow \mu \mathrm{MT}$ mice when compared with $\mu \mathrm{MT} / D r d 3^{+/+} \rightarrow \mu \mathrm{MT}$ mice (Fig. $4 \mathrm{~A}-\mathrm{C}$ ). To confirm whether DRD3-signalling actually favours the selective $\alpha 4$-integrin expression on B cells, we performed in vitro experiments in which $\operatorname{Drd3}^{+/+}$or $\operatorname{Drd3}^{-/-}$B cells were activated in the presence or the absence of dopamine, and 
the extent of CXCR3 and $\alpha 4$-integrin expression was analysed. The results show that B-cell stimulation with dopamine enhanced $\alpha 4$-integrin expression selectively, and that effect was abrogated in Drd3-deficient B cells (Additional file 1: Fig. S7), thereby confirming that DRD3signalling in B cells promotes $\alpha 4$-integrin expression. These results suggest that B-cell infiltration into the CNS may be impaired upon pMOG-induced EAE. Next, we addressed the possibility that DRD3 was regulating B-cell infiltration into the CNS upon pMOG-induced EAE. For this purpose, using congenic donor mice $\left(C d 45.1^{+/+} /\right.$ $\mathrm{Cd} 45.2^{-/-} / \mathrm{Drd} 3^{+/+}$and $\mathrm{Cd} 45.1^{-/-} / \mathrm{Cd} 45.2^{+/+} / \mathrm{Drd} 3^{-/-}$ mice), we generated chimeric BM mice harbouring both Drd3-sufficient and Drd3-deficient B cells (Fig. 4D). In these animals, EAE was induced with pMOG, and the extent of B cells from different genotypes was compared in the CNS as well as in the spleen and peripheral blood. Interestingly, whereas the frequency of Drd3-sufficient $B$ cells was increased in peripheral blood and the CNS upon EAE development, the frequency of Drd3-deficient $B$ cells remained unaltered in all tissues evaluated upon EAE-development (Fig. 4E). Moreover, the analysis of absolute numbers of B cells revealed that in healthy conditions, $\operatorname{Drd} 3$ deficiency resulted in a reduction in the number of B cells circulating through peripheral blood and the spleen, but with no significant effects in the CNS. Conversely, upon EAE development, Drd3 deficiency induced a selective decrease in the number of $\mathrm{B}$ cells infiltrating the CNS and without effect in the number of B cells circulating through peripheral blood and the spleen (Additional file 1: Fig. S8). To explore whether the differences observed between Drd3-sufficient and Drd3-deficient B lymphocytes in the frequency and number of cells infiltrating the different tissues analysed were due to an effect of DRD3 in proliferation or cell death, we performed experiments in which B-cell activation was induced in $\mathrm{Drd} 3^{+/+}$or $\mathrm{Drd} 3^{-/-} \mathrm{CD} 19^{+}$cells, and the extent of proliferation and viability were determined. The results showed that Drd3 deficiency resulted in a slight increase in B-cell proliferation and without effect in cell death (Fig. 4F, G), thereby ruling out the possibility that the reduction of cell number or frequency of Drd3-deficient B cells in the CNS was due to impaired proliferation or increased cell death. Thus, these results suggest that Drd3 deficiency in B cells results in reduced $\alpha 4$-integrin expression and, consequently, in impaired B-cell infiltration into the CNS upon pMOG-induced EAE. Since our results associated DRD3 to the B-cell subset $\mathrm{CD} 21^{+} \mathrm{CD}_{23}{ }^{+} \mathrm{IgM}^{+}$(Additional file 1: Fig. S3BD), which exerts anti-inflammatory activity in the CNS

(See figure on next page.)

Fig. 4 DRD3-signalling favours the expression of a4-integrin and attenuates the immunosuppressive profile in B cells infiltrating the CNS in an EAE model that does not depend on the APC-function of B cells. A-C BM chimeric mice harbouring Drd3-deficient (grey symbols) or Drd3-sufficient (white symbols) B cells were generated as described in Fig. 2A. Afterwards, EAE was induced in chimeric mice by immunization with pMOG $_{35-55}$ in CFA followed by pertussis toxin injection. $n=6-9$ mice per group. At the peak of disease severity (day 15 post-induction), mononuclear cells were isolated from the spleen and the CNS and the surface expression of CXCR3 and a4 integrin (CD49d) were analysed in the CD19+ population by flow cytometry. A Representative histograms for the expression of CXCR3 and CD49d in the CD19+ cells are shown. B Quantification of the mean fluorescence intensity (MFI) associated to the surface expression of CXCR3 and CD49d in living (ZAq ${ }^{-}$CD19 ${ }^{+}$cells isolated from the spleen (top panel) and CNS (bottom panel). C Quantification of the percentage of surface expression of CXCR3 and CD49d in living (ZAq $)^{-}$CD19+ cells isolated from the spleen (top panel) and CNS (bottom panel). (B-C) Each symbol represents data obtained from an individual mouse. The mean \pm SEM are depicted. ${ }^{*}, p<0.05 ;{ }^{* * *}, p<0.001$ by two-way ANOVA followed by Sidak's post hoc test. (D-E) BM chimeric mice harbouring Drd3-deficient and Drd3-sufficient B cells were generated by the i.v. transfer of a 1:1 mixed BM from Cd45. $1^{+/+} / C d 45.2^{-/-} / \mathrm{Drd} 3^{+/+}$mice (white symbols) and Cd45. $1^{-/-}$/

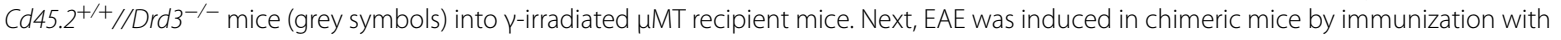
$\mathrm{pMOG}_{35-55}$ in CFA followed by pertussis toxin injection. D Schematic illustration of the experimental design. $\mathbf{E}$ At the peak of disease severity (day 15 post-induction), mononuclear cells were isolated from peripheral blood (left panel), the spleen (middle panel) and the CNS (right panel) and the frequency of total CD 19+ B cells was analysed by flow cytometry. Top panels show representative dot-plots of CD45.1 ${ }^{+}$versus CD45.2 $2^{+}$cells in the $\mathrm{CD} 19^{+}$gate. Numbers indicate the percentage of cells in the corresponding region. Bottom panels show the percentage quantification. $n=3-5$ mice per group. Each symbol represents data obtained from an individual mouse. The mean \pm SEM are depicted. Data representative from one out of two independent experiments are shown. ${ }^{*}$. $P<0.05 ;^{* *}, p<0.01,{ }^{* * * *}, p<0.0001$ by two-way ANOVA followed by Sidak's post hoc test. F, G Naïve B cells (CD19+ IgD ${ }^{\text {hi }}$ IgM $M^{\text {int }}$ CD 1 1 $c^{-}$TCR $\beta^{-}$) were isolated from the spleen of Drd3-deficient (grey symbols/histograms) or Drd3-sufficient (white symbols/histograms) mice by cell-sorting, loaded with cell-trace violet (CTV) and incubated in vitro in the presence of anti-CD40, anti-lgM, IFNY and the TLR9-ligand CpG for 5 days. F The extent of proliferation was evaluated as the dilution of the fluorescence associated to CTV in living $\left(\mathrm{ZAq}^{-}\right) \mathrm{CD} 19^{+}$cells by flow cytometry. Representative histograms are shown in the left panel. The marker indicates cells displaying dilution of CTV-associated fluorescence. Quantification of the percentage of cells displaying diluted CTV-associated fluorescence (top right panel) and the MFI of CTV-associated fluorescence (bottom right panel) are shown. G The extent of cell dead was determined as the percentage of ZAq ${ }^{+}$cells in the $\mathrm{CD} 19^{+}$gate. $\mathbf{F}, \mathbf{G}$ Each symbol represents data obtained from an individual mouse; $n=3$ mice per group. The mean \pm SEM are depicted. ${ }^{*}, p<0.05$ by unpaired two-tailed Student's t-test. n.s. non-significant. (H) Chimeric mice were treated as shown in $\mathbf{D}$ and at the peak of disease severity (day 15 post-induction), CD19+ B cells were isolated from the spleen and the levels of cytokine transcripts was analysed by qRT-PCR. The levels of gapdh transcripts were used as a housekeeping. Data were obtained from 4-6 mice per group. Each symbol represents data obtained from an individual mouse. The mean \pm SEM are depicted. Data representative from one out of two independent experiments are shown. ${ }^{*}, p<0.05 ;{ }^{* *}, p<0.01$ by two-way ANOVA followed by Sidak's post hoc test 
A
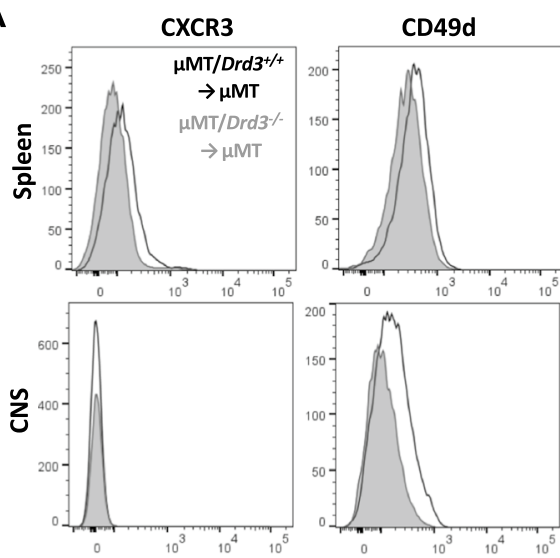

D

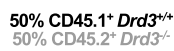

BM cells (i.v.)

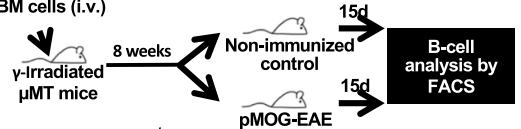

口 $\mathrm{CD}^{2} 5.1^{+} \mathrm{Drd}^{+/+}$ CD $45.2^{+}$Drd3 $^{-1-}$

E
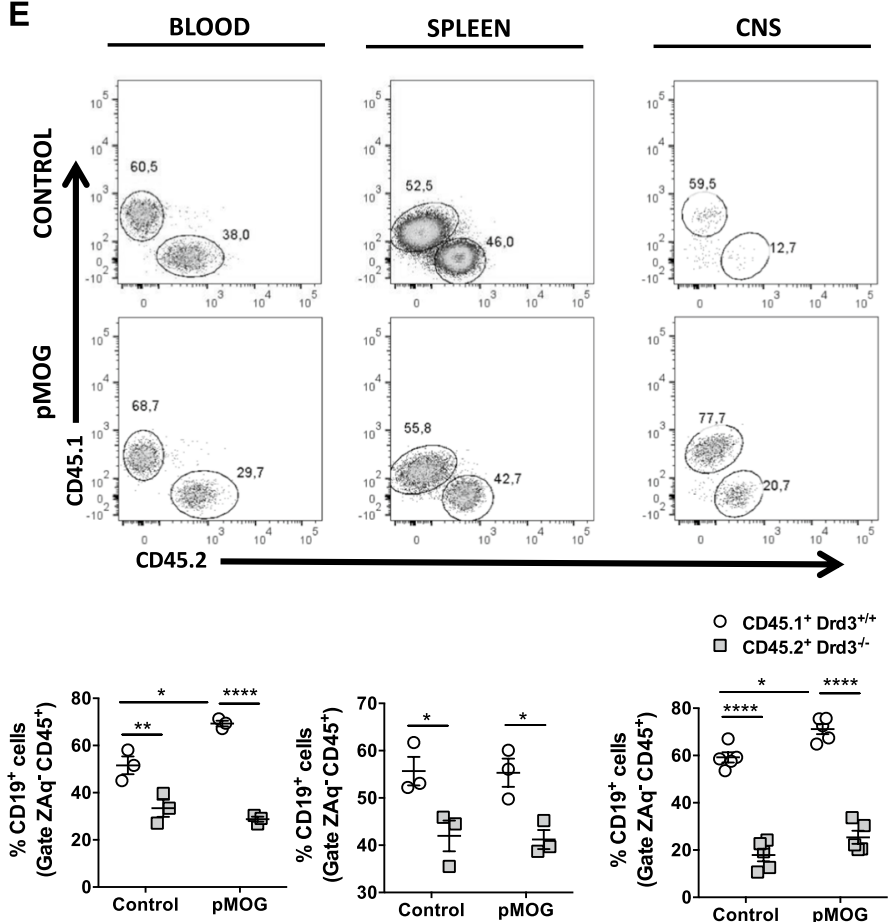

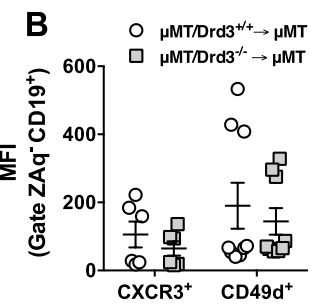

C
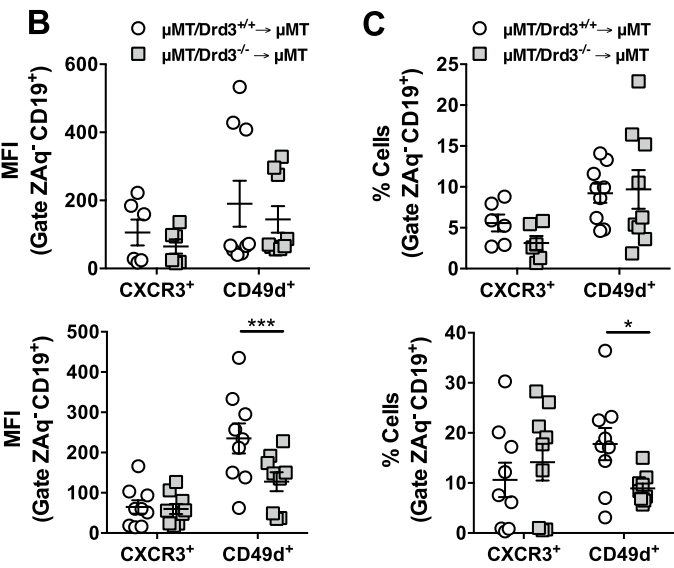

F
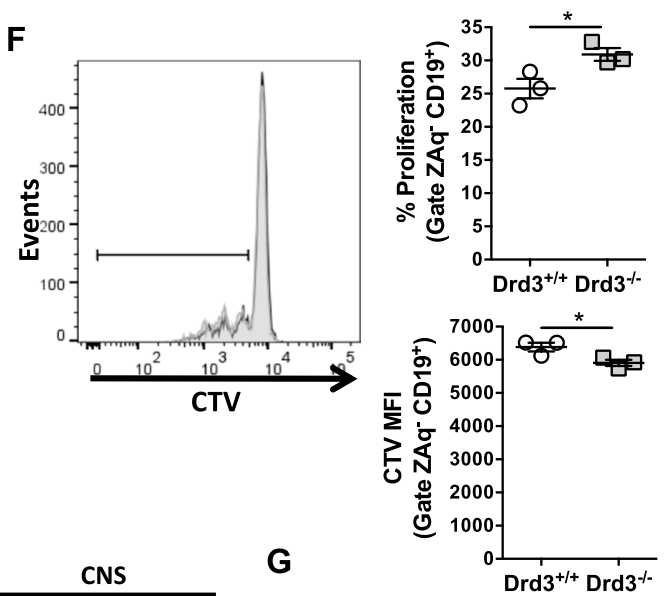

G

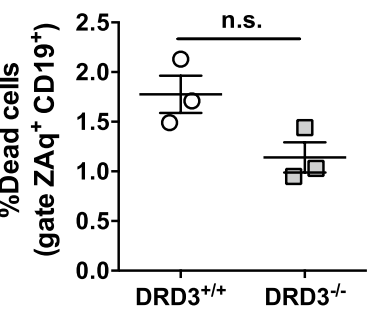

H

O CD45.1 ${ }^{+} \mathrm{Drd3}^{+/+}$

a CD45.2 ${ }^{+} \mathrm{Drd3}^{\text {t- }}$

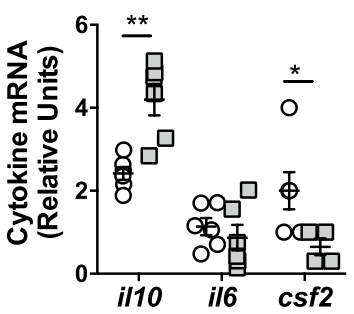

Fig. 4 (See legend on previous page.) 
in the pMOG-induced EAE model (Fig. 2), we reasoned that $\operatorname{Drd} 3$ deficiency should result in the accumulation of suppressive B cells in the spleen. Accordingly, we next sought to confirm the nature of cytokine produced by Drd3-deficient and Drd3-sufficient B cells retained in the periphery in this EAE model. For this purpose, at the peak of pMOG-induced EAE manifestation, CD45.1 ${ }^{+}$ and $\mathrm{CD} 45.2^{+} \mathrm{B}$ cells were isolated from the spleen by cell-sorting, and the transcripts encoding for pro-inflammatory and anti-inflammatory cytokines were quantified by qRT-PCR. The results show that $D r d 3$ deficiency in B cells exacerbated $i l 10$ transcription and reduced the expression of the mRNA encoding for GM-CSF (Fig. 4H). To confirm that DRD3-stimulation regulated the production of GM-CSF and IL-10 in B cells, we carried out in vitro experiments in which $B$ cells were activated in the presence or the absence of dopamine, and the extent of cytokine production was assessed by flow cytometry. However, the results show that cytokine production was very low in these in vitro conditions, and no relevant differences were found (Additional file 1: Fig. S9). Taken together, these results indicate that DRD3 in B cells is required to induce full CNS-tropism in B cells with antiinflammatory activity in a model of CNS autoimmunity that is independent of the APC-function of B cells.

\section{DRD3 favours the CXCR3 expression on B cells and their infiltration into the CNS in an EAE model that depends on the APC-function of $B$ cells}

Finally, we attempted to determine the mechanism by which DRD3 in B cells exerts a pro-inflammatory effect in the development of CNS autoimmunity in a model dependent of the APC-function of B cells. Since our results show that disease manifestation was completely abrogated in mice harbouring Drd3-deficient B cells in this animal model, we next evaluated the role of DRD3 in the ability of B cells to act as APC. Accordingly, EAE was induced in $\mu \mathrm{MT} / D r d 3^{-/-} \rightarrow \mu \mathrm{MT}$ and $\mu \mathrm{MT} / D r d 3^{+/+} \rightarrow \mu \mathrm{MT}$ mice using huMOG, and at the peak of disease manifestation, the extent of class II MHC expression was evaluated in splenic B cells, nevertheless, no significant differences were found between both experimental groups (Additional file 1: Fig. S10A-B). Furthermore, the APC ability of $\mathrm{Drd3} 3^{+/+}$ and $\mathrm{Drd}^{-/-}$B cells was evaluated in vitro using huMOGcoupled beads as antigen and $\mathrm{CD} 4^{+} \mathrm{T}$ cells expressing a MOG-specific TCR as described before [53]. The results show that Drd3 deficiency in B cells affected neither T-cell proliferation nor T-cell differentiation (Additional file 1: Fig. S10C-D). Similar conclusions were obtained when the APC-function of B cells was evaluated in vitro in the presence of dopamine at concentrations that stimulate DRD3 (Additional file 1: Fig. S11). Together, these results suggest that DRD3 was not relevant for APC-function of B cells upon huMOG-induced EAE. Since Drd3 deficiency in $\mathrm{B}$ cells affected the T-cell response only in the CNS, but not in the spleen (Fig. 3B-D) upon huMOG-induced EAE, we addressed the possibility that DRD3-signalling was affecting B-cell migration into the CNS in this model. Accordingly, EAE was induced with huMOG in $\mu \mathrm{MT} / D r d 3^{-/-} \rightarrow \mu \mathrm{MT}$ and $\mu \mathrm{MT} / D r d 3^{+/+} \rightarrow \mu \mathrm{MT}$ mice, and the extent of $\alpha 4$-integrin and CXCR3 expression was quantified in B cells infiltrating the CNS and the spleen

\footnotetext{
(See figure on next page.)

Fig. 5 Drd3 deficiency in B cells impairs the acquisition of CXCR3 and their infiltration into the CNS in an EAE model that depends on the APC-function of B cells. A-C BM chimeric mice harbouring Drd3-deficient (grey symbols) or Drd3-sufficient (white symbols) B cells were generated as described in Fig. 2A. Afterwards, EAE was induced in chimeric mice by immunization with huMOG in CFA followed by pertussis toxin injection. $n=3-6$ mice per group. At the peak of disease severity (day 15 post-induction), mononuclear cells were isolated from the spleen and the CNS and the surface expression of CXCR3 and a4 integrin (CD49d) were analysed in the CD19+ population by flow cytometry. A Representative histograms for the expression of CXCR3 and CD49d in the CD19+ cells are shown. Quantification of the MFI (B) and frequency (C) associated to the surface expression of CXCR3 and CD49d in living (ZAq ${ }^{-}$CD19+ cells isolated from the spleen (top panel) and CNS (bottom panel). B, C Each symbol represents data obtained from an individual mouse. The mean \pm SEM are depicted. ${ }^{* *}, p<0.01$ by two-way ANOVA followed by Sidak's post hoc test. D, E BM chimeric mice harbouring Drd3-deficient and Drd3-sufficient B cells were generated by the i.v. transfer of a 3:7 mixed BM from Cd45.1 +/ /

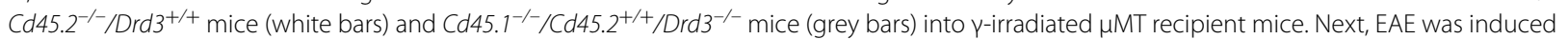
in chimeric mice by immunization with huMOG in CFA followed by pertussis toxin injection. D Schematic illustration of the experimental design. E At the peak of disease severity (day 15 post-induction), mononuclear cells were isolated from peripheral blood (left panels), the spleen (middle panels) and the CNS (right panels) and the frequency of total CD19+ B cells was analysed by flow cytometry. Top panels show representative dot-plots of CD45.1 $1^{+}$versus CD45.2 ${ }^{+}$cells in the CD19+ gate. Numbers indicate the percentage of cells in the corresponding region. Bottom panels show the percentage quantification. Each symbol represents data obtained from an individual mouse; $n=4-8$ mice per group. The mean \pm SEM are depicted. ${ }^{* *}, p<0.01,{ }^{* * *}, p<0.001,{ }^{* * * *}, p<0.0001$ by two-way ANOVA followed by Sidak's post hoc test. F, G Naïve B cells (CD19+ IgD ${ }^{\text {hi }}$ IgM ${ }^{\text {int }}$

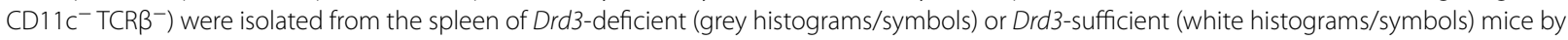
cell-sorting and incubated in vitro in the presence of anti-CD40, anti-lgM, IFNy and the TLR9-ligand CpG. After 5 days, CXCR3 and Tbet expression were evaluated by flow cytometry. F Representative histograms of CXCR3 and Tbet expression in the CD19+ population are shown in top panels. Quantification of the mean fluorescence intensity (MFI) associated to CXCR3 (bottom left panel) and Tbet (bottom right panel) are shown. G Quantification of the percentage of CD19+ $\mathrm{B}$ cells positive for CXCR3, Tbet or both are shown. F, G Each symbol represents data obtained from an individual mouse; $n=3$ mice per group. The mean \pm SEM are depicted. ${ }^{* *}, p<0.01$; by two-way ANOVA followed by Sidak's post hoc test
} 
(see the gating strategy in Figure S6). The results show that Drd3 deficiency in B cells resulted in increased frequency of CXCR3 expression in the spleen and reduced CXCR3 expression in the CNS, without effect in $\alpha 4$-integrin expression in any tissue (Fig. 5A-C). Thus, these results suggest that B-cell infiltration into the CNS may be impaired by $\operatorname{Drd} 3$ deficiency upon huMOG-induced EAE.

Next, we addressed the possibility that DRD3 was regulating B-cell infiltration into the CNS upon huMOGinduced EAE. For this purpose, using congenic donor mice $\left(C d 45.1^{-/-} / C d 45.2^{+/+} / D r d 3^{-/-}\right.$and $C d 45.1^{+/+} /$ $C d 45.2^{-/-} / \mathrm{Drd} 3^{+/+}$mice), we generated chimeric BM mice harbouring both Drd3-sufficient and Drd3-deficient B cells (Fig. 5D). Because the transfer of $D r d 3^{+/+}$. to-Drd3 $3^{-/}$BM at the 1:1 ratio resulted in decreased Drd3-deficient B cells in steady-state (Fig. 4D, E), in these experiments, we carried out the transfer of $\mathrm{Drd3}^{+/+}$. to-Drd3 ${ }^{-1-}$ BM at 3:7 ratio. In these animals, EAE was induced with huMOG, and the extent of B cells from different genotypes was compared in the CNS as well as in the spleen and peripheral blood. The results show that frequency of Drd3-sufficient B cells was significantly increased in the CNS upon EAE development, whilst it was not changed in Drd3-deficient B cells (Fig. 5E). On the other hand, whereas the frequency of $D r d 3^{-/-}$B cells was higher than $\mathrm{Drd} 3^{+/+}$B cells in the periphery upon steady-state, only $\mathrm{Drd} 3^{-/-}$B cells were reduced in frequency in peripheral blood and the spleen upon huMOG-induced EAE (Fig. 5E). Thus, these results suggest that Drd3 deficiency in B cells results in altered CXCR3 expression and thereby impaired B-cell infiltration into the CNS upon huMOG-induced EAE. To gain a deeper mechanistic insight into the role of DRD3 in CXCR3 expression on B cells, we performed in vitro B-cell activation assay induced by anti-CD40, anti-IgM, IFN $\gamma$, and the TLR9-ligand CpG [60-62]. Since CXCR3 expression is dependent on the activity of the transcription factor Tbet in B cells [63], we activated naïve B cells isolated from $\mathrm{Drd3}^{+/+}$and $\mathrm{Drd} 3^{-/-}$mice, and the extent of CXCR3 and Tbet expression was determined by flow cytometry. The results show that $\operatorname{Drd} 3$ deficiency resulted in reduced frequency and density of CXCR3 expression without effect on Tbet expression (Fig. 5F, G), thus indicating that DRD3-signalling promotes CXCR3 expression downstream Tbet action. Together these results suggest that DRD3 promotes CXCR3 expression on pro-inflammatory B cells and the consequent infiltration into the CNS upon huMOG- induced EAE.

\section{Discussion}

Our findings demonstrated an important role of dopaminergic stimulation mediated by DRD3 in promoting the infiltration of pro-inflammatory and anti-inflammatory B cells in the CNS in two different animal models of CNS autoimmunity.

Interestingly our data show that the frequency of $\mathrm{DRD}^{+} \mathrm{B}$ cells was selectively increased in the CNS upon huMOG-induced EAE. Further phenotypical analysis shows that the only B-cell population expressing DRD3 in the CNS in this EAE model was the $\mathrm{CD} 20^{+} \mathrm{MHC}^{-\mathrm{II}^{+}}$ subset. A previous study shows that this B-cell population exerts a fundamental function as APC in the CNS upon huMOG-induced EAE [38]. Nevertheless, it is important to consider that MHC-II expression in B cells is also required for the production of T-cell-dependent autoantibodies [64-66]. According to the fundamental function of $\mathrm{CD} 2 \mathrm{O}^{+} \mathrm{MHC}-\mathrm{II}^{+} \mathrm{B}$ cells in $\mathrm{CNS}$ autoimmunity and to the important role of DRD3 favouring the infiltration of these B cells in the CNS, Drd3 deficiency in $B$ cells abrogated disease manifestation completely and strongly reduced the frequency of inflammatory $\mathrm{CD} 4^{+} \mathrm{T}$ cells in this animal model (Fig. 3).

Our mechanistic analysis showed that DRD3 was not necessary for APC-function of B cells but was required to induce an efficient CNS-tropism in this B-cell subset. This DRD3-induced CNS-tropism was mediated by an upregulation of CXCR3 expression. According to these findings, a recent study showed that B cells expressing CXCR3 were enriched in the CNS of MS patients [63]. Moreover, the treatment of MS patients with a clinically effective drug, natalizumab, which avoids lymphocytes infiltration into the CNS, decreased the accumulation of $\mathrm{CXCR}^{+}{ }^{+} \mathrm{B}$ cells into the CNS [63]. Interestingly, IFNY might induce the expression of the transcription factor Tbet, which promotes the expression of CXCR3 in lymphocytes, including $\mathrm{B}$ cells. This chemokine receptor confers responsiveness to the chemokines CXCL9, CXCL10, and CXCL11, which are produced at high levels in sites of inflammation in response to IFNY [67]. Our results showed that $\mathrm{Drd} 3$ deficiency in B cells attenuated the expression of CXCR3 without effects in the level of Tbet expression, indicating that DRD3 in B cells favours CXCR3 expression downstream Tbet.

Using a model of CNS autoimmunity in which the APC-function of B cells is irrelevant, we found another important regulatory effect of DRD3 in the control of B-cell function. Our data show that Drd3 deficiency in $B$ cells resulted in exacerbated disease manifestation and increased frequency of $\mathrm{CD} 4^{+} \mathrm{T}$ cells producing $\mathrm{GM}$ CSF in the CNS upon pMOG-induced EAE. Of note, it has been demonstrated that GM-CSF is the most proinflammatory cytokine produced by $\mathrm{CD} 4^{+} \mathrm{T}$ cells in the CNS. In contrast to IL-17 and IFN $\gamma$, GM-CSF is essential to promote EAE manifestation [57]. Thereby, our results suggested that DRD3 stimulation favoured the function of B cells with anti-inflammatory activity in 
A

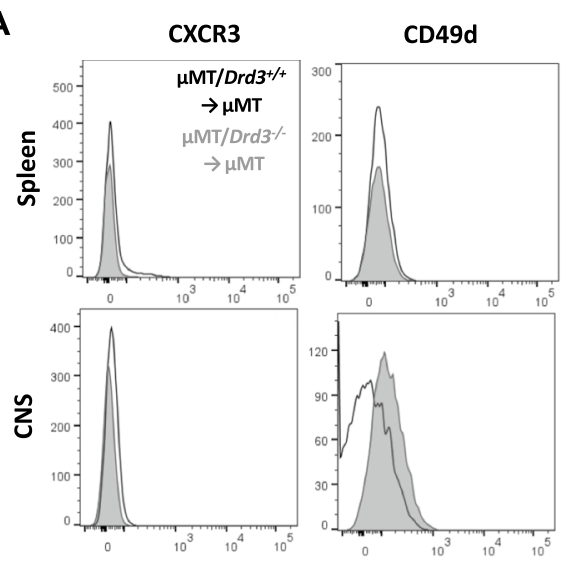

D

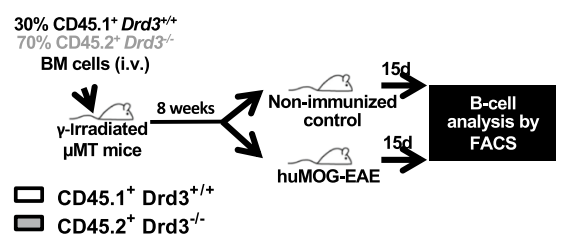

F
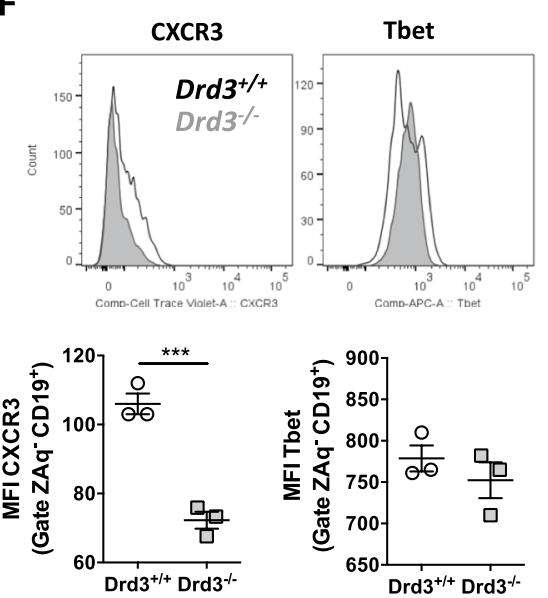

G

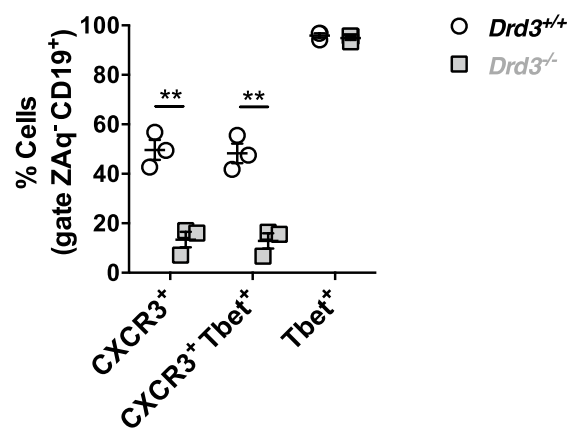

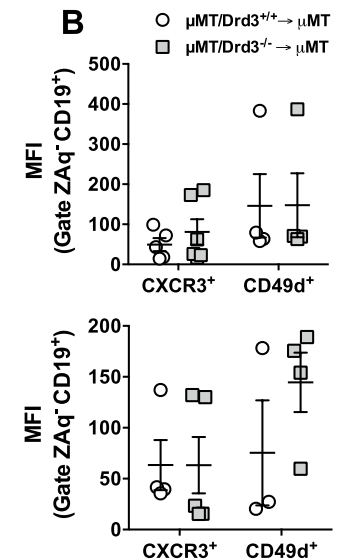
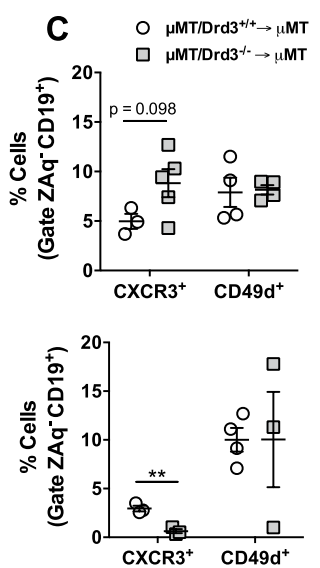

E
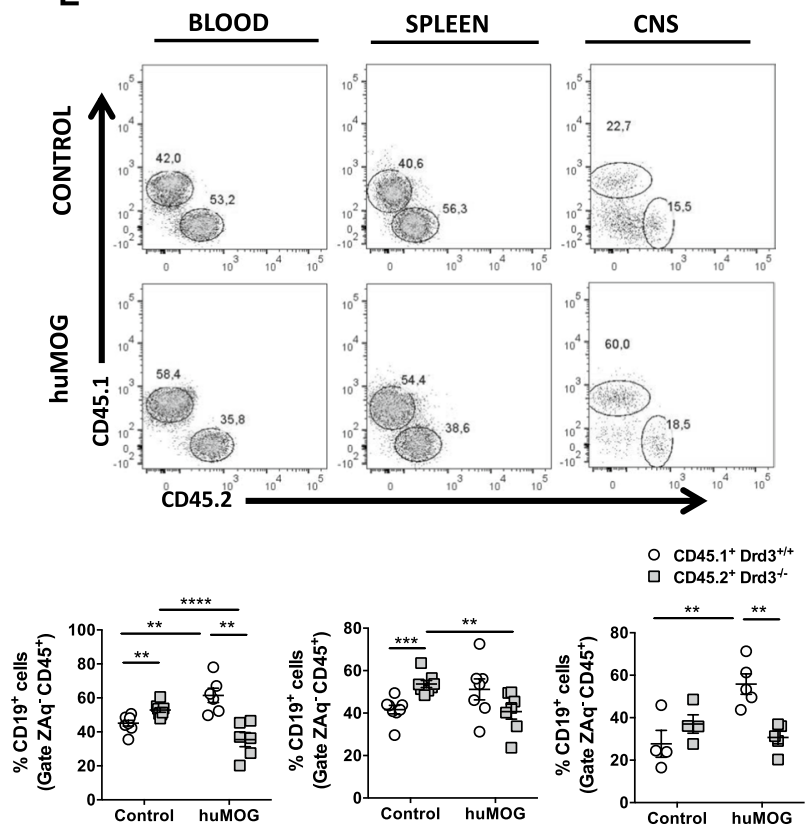

Fig. 5 (See legend on previous page.) 
the CNS. In this regard, three different subsets of B cells with immunosuppressive function have been described so far, including $\mathrm{CD} 1 \mathrm{~d}^{+} \mathrm{CD}^{+}$(also called B10) [35, 68], $\mathrm{CD} 138^{+} \mathrm{CD}_{4} 4^{+}$[69] and $\mathrm{CD} 21^{+} \mathrm{CD}_{23}{ }^{+} \mathrm{IgM}^{+} \mathrm{B}$ cells [55]. All of these subsets of regulatory $B$ cells exert immunosuppressive effects, attenuating the T-cell-mediated inflammation, which is mediated by IL-10. Interestingly, we observed that $\mathrm{CD} 21^{+} \mathrm{CD} 23^{+} \mathrm{IgM}^{+}$was the only subset of regulatory $\mathrm{B}$ cells detectable in the CNS upon pMOG-induced EAE, whilst $\mathrm{CD} 1 \mathrm{~d}^{+} \mathrm{CD}^{+}$and $\mathrm{CD} 138^{+}$ $\mathrm{CD}_{4} 4^{+}$subsets were barely detectable in these conditions. In addition, $\mathrm{CD} 21^{+} \mathrm{CD} 23^{+} \mathrm{IgM}^{+} \mathrm{B}$ cells were the only subset of regulatory $\mathrm{B}$ cells expressing detectable levels of DRD3 on the cell surface upon pMOG-induced EAE. Further analysis showed that DRD3 was necessary to induce the upregulation of $\alpha 4$-integrin (CD49d) on the cell surface and the subsequent B-cell infiltration into the CNS upon pMOG-induced EAE. Importantly, the $\alpha 4$-integrin together $\beta 1$-integrin (CD29) form a heterodimeric complex on the lymphocyte surface that recognizes its ligand, the vascular cell adhesion protein 1 (VCAM-1) expressed in the blood-brain barrier, allowing the lymphocyte infiltration into the CNS [70, 71]. Notably, the genetic deficiency of $\alpha 4$-integrin restricted to the $\mathrm{CD} 19^{+} \mathrm{B}$ cells resulted in exacerbated CNS autoimmunity in a model of pMOG-induced EAE [72], indicating the high relevance of $\alpha 4$-integrin in the infiltration of regulatory B cells into the CNS in this EAE model. Accordingly, our results showed that $D r d 3$ deficiency in $B$ cells not only resulted in impaired $\alpha 4$-integrin expression and reduced B-cell infiltration into the CNS, but also in the accumulation of $\mathrm{B}$ cells displaying immunosuppressive potential (higher il10 and lower $c f s 2$ transcription) in the periphery.

Although the pMOG-induced EAE model represents a proper experimental system to study B cells' regulatory role irrespective of their APC-function in the CNS, the huMOG-induced EAE model mimics better the B-cell participation in MS. According to this notion, it has been shown that natalizumab, an anti- $\alpha 4$-integrin monoclonal antibody, exerts an efficient therapeutic effect reducing disease manifestation in relapsing-remitting MS patients $[59,73]$. Agree with this observation in human patients, mice harbouring $\alpha 4$-integrin-deficient B cells display a significant reduction in disease manifestation upon huMOG-induced EAE model [74]. In contrast to the results observed in MS patients, the genetic deficiency of $\alpha 4$-integrin in $B$ cells resulted in exacerbated disease manifestation in a pMOG-induced EAE model [72]. Another aspect supporting the idea that huMOGinduced EAE is a proper experimental system to study B-cell participation in MS is based on CXCR3. According to the relevant role of CXCR3 in the infiltration of inflammatory B cells observed here upon huMOGinduced EAE, CXCR3 has been found highly expressed on B cells obtained from the CSF, meninges, and brain of MS patients [59, 63]. In addition, the treatment of patients with natalizumab, which exerts an efficient therapeutic effect, reduced the accumulation of $\mathrm{CXCR}^{+} \mathrm{B}$ cells into the CNS [63].

Dopaminergic signalling has been previously involved in the control of migration of other cells of the immune system. A recent study described that DRD4-stimulation induced an upregulation of CCR5 in human macrophages and thus increasing their migratory ability to infiltrate the brain [74]. Conversely, signalling through DRD1 was identified as a negative regulator of CCR5 expression [74]. According to these results, the inhibition of dopamine synthesis induced by $\alpha$-methylparatyrosine resulted in a decreased recruitment of peripheral monocytes into the nigrostriatal pathway in a mouse model of Parkinson's disease [75]. In addition, addressing the role of dopamine in the migration of lymphocytes, Watanabe et al. have provided pharmacologic evidence suggesting that DRD3-signalling favours $\mathrm{CD}^{+}{ }^{+} \mathrm{T}$-cell migration in response to CCL19, CCL21, and CXCL12 [76]. According to the role of CCR7 (receptor for CCL19 and CCL21) in the recirculation of naïve $T$ cells into the lymph nodes throughout the body, the systemic antagonism of DRD3 decreased the recruitment of naïve $\mathrm{CD}^{+} \mathrm{T}$-cell into the lymph nodes [76]. Moreover, another work provided pharmacologic evidence supporting the notion that DRD5-signalling reduces CCR4 expression in Treg and thereby, attenuates the recruitment of these cells to CCL22 [77]. In addition, we recently found that DRD3signalling down-regulates CCR9 expression on Treg, thus limiting their recruitment into the inflamed gut mucosa and consequently exacerbating inflammatory colitis [15]. Here, we provide in vivo evidence using genetic approaches demonstrating that DRD3 in B cells mediates the upregulation of CXCR3 and $\alpha 4$-integrin, thus affecting the recruitment of important B-cell subsets into the CNS upon the development of CNS autoimmunity.

Interestingly, we recently found that DRD5 might be assembled with CCR9 in inflammatory $\mathrm{T}$ cells, conforming a CCR9:DRD5 heteromeric receptor that drives the recruitment of these cells into the gut mucosa upon inflammation [78]. The stimulation of the CCR9:DRD5 heteromer exerts a biological function different from those downstream functions triggered by the isolated forms of CCR9 or DRD5, thus constituting a new cell surface sensor. This phenomenon raises the possibility that under certain circumstances, DRD3 could be part of a heteromeric receptor on $\mathrm{B}$ cells, which might explain why, in some cases, there were disparities between the in vitro DRD3-stimulation experiments and the in vivo 
DRD3 deficiency experiments. Nevertheless, to confirm this possibility, further experimental research is necessary.

Regarding the role of dopaminergic signalling in lymphocytes inside the CNS during EAE, evidence suggests that high dopamine levels attenuate the inflammatory potential of these cells [2]. Consistent with this idea, the systemic administration of a monoaminoxidase inhibitor, which induces a significant increase of dopamine levels in the brain and spinal cord, dampens the development of EAE manifestation in mice [79]. Of note, this effect was not due to an alteration in the extent of T-cell infiltration in the CNS [79]. Conversely, the reduction of striatal dopamine levels exerted by the treatment of mice with MPTP prior EAE induction results in exacerbated disease manifestation [22].

Considering the anti-inflammatory effect reported for DRD2 stimulation $[1,2]$, the expression of DRD2 in B cells (Additional file 1: Fig. S5) [48], and the dominant action of DRD2-signalling over DRD3-signalling [49], it is possible to speculate that CNS areas maintaining high dopamine levels $\left(\geq 10^{-6} \mathrm{M}\right)$, including the hippocampus, paraventricular nucleus, striatum and retina [23], would promote an anti-inflammatory effect mediated by DRD2 on B cells under homeostatic conditions. However, CNS areas that involve a reduction of dopamine levels upon EAE in rodents, such as the spinal cord and the striatum [23], would promote the selective DRD3 stimulation on B cells.

In this regard, DRD3-stimulation in Breg infiltrating the striatum and spinal cord would promote a higher anti-inflammatory function. Since no alterations of APC-function of inflammatory B cells were found due to $\operatorname{Drd} 3$ deficiency, it is tempting to speculate that the selective DRD3-stimulation in B cells with APC-function infiltrating the striatum and spinal cord would not affect the inflammatory potential of these cells. However, the DRD3-stimulation on B cells with APC-function in peripheral tissues where dopamine levels are low $\left(10^{-9}-10^{-7} \mathrm{M}\right)$, such as plasma, bone marrow, or spleen [23], would promote a higher infiltration of these inflammatory cells into the CNS (Figs. 3, 5) upon EAE development, thus exacerbating the disease severity.

\section{Conclusions}

Our findings demonstrate here for the first time how dopaminergic stimulation in B cells exerts an important regulation in the development of CNS autoimmunity. First, through DRD3, dopamine favours the CNS-tropism in a pro-inflammatory B-cell subset with APC-function, thus contributing to the re-stimulation of encephalitogenic effector $\mathrm{CD}_{4}^{+} \mathrm{T}$ cells and thereby reinforcing $\mathrm{CNS}$ autoimmunity. Secondly, when B cells with APC-function are negligible, DRD3-signalling promotes CNS-homing of B cells with anti-inflammatory features and, consequently, dampens the T-cell-mediated autoimmunity.

\section{Abbreviations}

ACK: Ammonium-chloride-potassium; Ab: Antibody; APC: Antigen-presenting cells; BCR: B-cell receptor; BM: Bone marrow; CNS: Central nervous system; CDn: Cluster of differentiation $n$; DCs: Dendritic cells; dLN: Draining lymph nodes; DR: Dopamine receptor; DR Dn: DRDn; EAE: Experimental autoimmune encephalomyelitis; huMOG: Human MOG; MFI: Mean fluorescence intensity; MOG: Myelin oligodendrocyte glycoprotein; MS: Multiple sclerosis; $\mathrm{PMOG}_{35-55}$ : Peptide MOG $_{35-55}$; PBMC: Peripheral blood mononuclear cells; Rag1: Recombination activating gene 1; Tregs: Regulatory T cells; Tbet: T-box transcription factor encoded by TBX21; Thn:Thelper n; VCAM-1: Vascular cell adhesion molecule 1.

\section{Supplementary Information}

The online version contains supplementary material available at https://doi. org/10.1186/s12974-021-02338-1.

Additional file 1: Figure S1. B-cell infiltration into the CNS correlates with the EAE clinical score (associated to Fig. 1). EAE was induced in C57BL/6 mice $(n=6)$. A group of control mice were treated only with PBS $(n=2)$. At day 15 post-induction, mice were killed and the extent of $B$ cells infiltrating the brain was analysed by immunofluorescence. (A) Representative images of immunofluorescence for CD19 in mice displaying clinical score 0 (left panel, healthy control), 2 (middle panel, EAE) and 3 (right panel, EAE). Arrow heads showing some CD19 ${ }^{+}$cells in the tissue. Bar, $200 \mu \mathrm{m}$. Inserts in the down-left corner show some B cells in higher magnification. (B) The number of CD19 ${ }^{+}$cells per area was quantified in the cortex ( $n=3$ slides per mouse) and a correlation analysis was performed with the clinical score. The R2 and $p$ value were calculated with Pearson's correlation coefficient. Figure S2. Analysis of DRD3 expression in B cells upon EAE development (associated to Fig. 1). EAE was induced in wild-type $\mathrm{C} 57 \mathrm{BL} / 6$ mice by immunization with $\mathrm{pMOG}_{35-55}$ or huMOG in CFA followed by pertussis toxin injection. At the peak of disease severity, mononuclear cells were isolated from the spleen, draining lymph nodes (dLN) and central nervous system (CNS) and DRD3 expression was evaluated in the $\mathrm{CD} 19^{+}$population by flow cytometry. (A) Gating strategy. Numbers indicate the percentage of cells inside the selected region. (B) Representative dot plots showing the gate of $\mathrm{CD} 19^{+}$cells from each tissue selected for the analysis of DRD3 expression. Numbers indicate the percentage of CD19 ${ }^{+}$cells. (C) Quantification of the mean fluorescence intensity (MFI) associated to DRD3 immunostaining. Left panels show representative histograms. Unspecific (black lined) histograms corresponds to controls in which anti-DRD3 antibody was pre-incubated with the antigenic peptide (used as immunogen to develop the antibody) to avoid specific binding on the cell surface. Right panels show the quantification of the MFI in the CD19 ${ }^{+}$gate. Each symbol represents data obtained from an individual mouse; $n=2-3$ mice per group. The mean \pm SEM are depicted. ${ }^{* *}, p<0.001 ;{ }^{* * * *}, p<0.0001$ by one-way ANOVA followed by Tukey's post hoc test. Figure S3. Distribution and DRD3 expression of B-cell subpopulations upon EAE development (associated to figure 1). EAE was induced in C57BL/6 mice by immunization with $\mathrm{PMOG}_{35-55}$ or huMOG in CFA followed by pertussis toxin injection. Disease severity was evaluated as clinical score during the time-course of the disease development. At maximum disease severity (score 3), mononuclear cells were isolated from Spleen, draining lymph node (dLN) and Central nervous system (CNS). (A) Representative dot plots showing the frequency of B cells (CD19+ ${ }^{+}$cells) observed in the analysed tissues. (B) Representative dot plots indicating different B-cell subpopulations analysed from the $\mathrm{CD}_{19}{ }^{+}$gate. ( $C$ and $\left.\mathrm{D}\right)$ the frequency (C) and the percentage of DRD3 expression (D) in different subpopulations of $\mathrm{CD} 19^{+} \mathrm{B}$ cells were evaluated. Data representative from one out of three independent experiments are shown. Values represent mean \pm SEM 
from $3-5$ mice per group. *, $p<0.05: * *, p<0.01{ }^{* * *}, p<p .001 * * * *, p<0.0001$ by one-way ANOVA followed by Tukey's post hoc test. Figure S4. Analysis of leukocyte populations in bone marrow chimeric mice harbouring Drd3 deficiency restricted to $B$ cells (associated to figure 2 and 3 ). $\mu \mathrm{MT}$ recipient mice were $\gamma$-irradiated with 1100 rads and $24 \mathrm{~h}$ later reconstituted with a bone marrow mixture (107 total cells per mouse) conformed by $80 \%$ obtained from $\mu$ MT mice and $20 \%$ obtained from $\mathrm{Drd}^{+/+}$or $20 \%$ Drd3 ${ }^{-/}$mice (see an scheme in figure 2A). Eight weeks after BM-transfer, leukocyte populations were analysed in peripheral blood by flow cytometry. Quantification of the absolute number of Drd3-sufficient and Drd3-deficient leukocyte populations is shown. Each symbol represents data obtained from an individual mouse; $n=4-5$ mice per group. The mean \pm SEM are depicted. Not significant differences were detected between both genotypes. Figure S5. Drd3 deficiency does not affect the expression of other components of the dopaminergic system in B cells (associated to figure 1). The expression of tyrosine hydroxylase ( $T H$, left panels), dopamine receptor D2 (DRD2, middle panels) and dopamine receptor D5 (DRD5, right panels) was analysed in the CD19+ population in Drd3-sufficient (black lines) and Drd3-deficient (green lines) splenic B cells by flow cytometry. TH immunostaining was performed in permeabilized cells whilst DRD2 and DRD5 immunostaining was carried out in non-permeabilized cells. Top panels show representative histograms. The grey histograms represent negative controls of immunostaining: an isotype-matched control in the case of TH (left panel), or the pre-treatment of the anti-DRD2 or anti-DRD5 antibodies with the specific antigenic peptide recognized by the respective antibody (middle and right panels). Bottom panels show the quantification of the MFI associated to the immunostaining normalized by the MFI associated to negative control (In-fold). The dotted line shows in-fold $=1$, which indicates no expression. Each symbol represents data obtained from an individual mouse; $n=4$ mice per group. The mean \pm SEM are depicted. Not significant differences were detected between both genotypes. Figure S6. Gating strategy to analyse surface expression of homing molecules in B cells (associated to figure 4 and 5). (A) Representative dot-plots showing the gating strategy to analyse surface expression of homing molecules in splenic B cells isolated from Drd3-sufficient mice. Numbers indicate the percentage of cells inside the selected region. (B) Representative dot plots showing the analysis of expression of homing molecules in B cells selected as in (A). Left panel shows the fluorescence associated to CXCR3 (BV421) and CD49d (PE) immunostaining. Middle panel shows the FMO for the BV421 channel, whilst right panel shows the FMO for the PE channel. Numbers indicate the percentage of cells inside the corresponding quadrant. (C) Representative histograms showing the fluorescence associated to CXCR3 immunostaining (left panel) and CD49d immunostaining (right panel). Black lined histograms represent fluorescence associated to FMO, whilst red lined histograms represent fluorescence associated to CXCR3 and CD49d immunostaining, respectively. Figure S7. Drd3-signalling increases CD49d expression in B cells (associated to figure 4). CD19+ IgMint CD11 $C^{-}{ }^{-T C R} \beta^{-}$cells were isolated by cell-sorting and then in vitro activated in the absence (control) or in the presence of $500 \mathrm{nM}$ Dopamine (Dopamine) for 48h. Afterwards, the extent of surface expression of CXCR3 (left panel) or CD49d (right panel) was analysed by flow cytometry. (A) Representative histograms. (B) Quantification. Values are the mean fluorescence intensity (MFI) associated to the immunostaining of CXCR3 (left panel) or CD49d (right panel) of $\mathrm{ZAq}^{-} \mathrm{CD}_{19}{ }^{+}$cells. Each symbol represents data obtained from an individual mouse; $n=3-6$ mice per group. The mean \pm SEM are depicted. *, $p<0.05$ by two-way ANOVA followed by Sidak's post hoc test. Figure S8. Drd3 deficiency results in reduced number of $B$ cells under homeostasis or upon EAE induction (associated to figure 4). Chimeric mice were generated and treated as shown in figure 4D and, at the peak of disease severity (day 15 post-induction), mononuclear cells were isolated from peripheral blood (left panel), the spleen (middle panel) and the CNS (right panel) and the absolute number of $C D 19+B$ cells was quantified by flow cytometry. Each symbol represents data obtained from an individual mouse; $n=4$ mice per group. The mean \pm SEM are depicted. *, $p<0.05 ;{ }^{* *} . P<0.011^{* * *}, p<0.001,{ }^{* * * *}$, $p<0.0001$ by two-way ANOVA followed by Sidak's post hoc test. Figure S9. Analysis of cytokine production by activated B cells in the presence of dopamine (associated to figure 4). Drd3-sufficient or Drd3-deficient CD19+
IgM ${ }^{\text {int }}$ CD11 $c^{-}$TCR $\beta^{-}$cells were isolated from the spleen by cell-sorting and then in vitro activated in the absence (control) or in the presence of 500 nM Dopamine (Dopamine) for $5 \mathrm{~d}$. Afterwards, cells were re-stimulated with PMA and ionomycin in the presence of brefeldin A for $4 \mathrm{~h}$ and the extent of IL-10, IL-6 and GM-CSF production was assessed by intracellular cytokine immunostaining and analysed by flow cytometry. (A) Representative dot-plots are shown. (B) Quantification. Values are the percentage of cells producing the corresponding cytokine in the $\mathrm{ZAq}^{-} \mathrm{CD}_{1} 9^{+}$gate. Each symbol represents data obtained from an individual mouse; $n=5-7$ mice per group. The mean \pm SEM are depicted. *, $p<0.05$ by two-way ANOVA followed by Sidak's post hoc test. Figure S10. Drd3 deficiency in B cells does not impair antigen-presentation to $T$ cells (associated to figures 4 and 5). (A and B) MHC-Il expression was evaluated by Flow cytometry analysis in splenic CD19+ $B$ cells obtained from $\mu \mathrm{MT} / \mathrm{Drd}^{+/ /+}$or $\mu \mathrm{MT} / \mathrm{Drd} 3^{-/-}$chimeric mice immunized with (A) pMOG or (B) huMOG. (C-D) In vitro antigen-presentation assays. 2D2 CD4 ${ }^{+}$ T cells, which express the transgenic TCR specific for recognizing the peptide $\mathrm{PMOG}_{35-55}$ on IA , were loaded with the fluorescent probe Cell Trace Violet (CTV). B cells were pulsed with (C) pMOG-beads or (D) huMOG-beads overnight and then co-cultured with CTV-loaded 2D2 $\mathrm{CD}^{+} \mathrm{T}$ cells. After 5 days, proliferation as well as cytokine production were determined by flow cytometry in living ( $\left(\mathrm{Aq}^{-}\right) \mathrm{CD}^{+} \mathrm{T}$ cells. Each symbol represents data obtained from an individual mouse; $n=3-9$ mice per group. The mean \pm SEM are depicted. Not significant differences were detected between both genotypes. Figure S11. (associated to figure 5). Drd3-signalling in B cells acting as APC does not affect the extent of cytokine production by T cells. Drd3-sufficient or Drd3-deficient CD19+ IgM ${ }^{\text {int }}$ CD11 $c^{-}$TCR $\beta^{-}$cells were isolated by cell-sorting and then in vitro pulsed with the antigen in the absence (control) or in the presence of 500 nM Dopamine (Dopamine) for $2 \mathrm{~h}$. Afterwards, B cells were washed and co-cultured with $2 \mathrm{D} 2 \mathrm{CD}^{+} \mathrm{T}$ cells, which were previously loaded with the fluorescent probe Cell Trace Violet (CTV). After 5 days, cells were re-stimulated with PMA and ionomycin for $5 \mathrm{~h}$ in the presence of brefeldin $A$, and the extent of IL-17 (A), GM-CSF (B) and IFN- $\gamma$ (C) production was determined by intracellular cytokine staining in the living ( $\left(\mathrm{Aq}^{-}\right) \mathrm{CD}^{+}$ population. The expression of Foxp3 in the living (ZAq) $\mathrm{CD}^{+}{ }^{+}$-cell population was assessed by intracellular immunostaining followed by flow cytometry (D). The extent of proliferation of living ( $\left.\mathrm{ZAq})^{-}\right) \mathrm{CD}^{+}{ }^{+} \mathrm{T}$ cells was evaluated as the percentage of cells displaying dilution of the fluorescence associated to CTV by flow cytometry (E). Top panel shows representative histograms; bottom panel shows the quantification. (A-E) Each symbol represents data obtained from an individual mouse; $n=4-5$ mice per group. The mean \pm SEM are depicted. Not significant differences were detected between genotypes or treatments.

\section{Acknowledgements}

We thank Miss María José Fuenzalida for her technical assistance in cell-sorting and Dr. Sebastián Valenzuela for his valuable veterinary assistance in our animal facility. We thank Dr. Marc Caron for providing Drd3 ${ }^{-/-}$mice.

\section{Authors' contributions}

C.P. and R.P. designed the study. C.P, F.O.B, P.F., A.E. and J.J.S. conducted experiments and acquired data. C.P and R.P. analysed data. M.I.Y. provided new reagents. C.P and R.P. wrote the manuscript. All authors read and approved the final manuscript.

\section{Funding}

This work was supported by "Financiamiento Basal para Centros Científicos y Tecnológicos de Excelencia" (Centro Ciencia \& Vida; FB210008) and by the grants FONDECYT-3160383 (to C.P.) and FONDECYT-1210013 (to R.P.) from "Agencia Nacional de Investigación y Desarrollo de Chile (ANID)".

\section{Availability of data and materials}

The datasets used and/or analysed during the current study are available from the corresponding author on reasonable request. 


\section{Declarations}

\section{Ethics approval and consent to participate}

All procedures and housing were compliant with the recommendations in the 8th edition of the Guide for the Care and Use of Laboratory Animals and with the United States Public Health Service Policy. The protocol was approved by the IACUC of Fundación Ciencia \& Vida (Permit Number: P009-2019).

\section{Consent for publication}

Not applicable.

\section{Competing interests}

The authors declare that they have no competing interests.

\section{Author details}

'Laboratorio de Neuroinmunología, Centro Ciencia \& Vida, Fundación Ciencia \& Vida, Avenida Zañartu \#1482, Ñuñoa, 7780272 Santiago, Chile. ${ }^{2}$ Facultad de Medicina y Ciencia, Universidad San Sebastián, Providencia, 7510156 Santiago, Chile. ${ }^{3}$ Laboratory of Immune Cell Biology, Department of Cellular and Molecular Biology, Pontificia Universidad Católica de Chile, 8330025 Santiago, Chile.

Received: 10 May 2021 Accepted: 2 December 2021

Published online: 17 December 2021

\section{References}

1. Pacheco R, Contreras F, Zouali M. The dopaminergic system in autoimmune diseases. Front Immunol. 2014;5:117

2. Vidal PM, Pacheco R. Targeting the dopaminergic system in autoimmunity. J Neuroimmune Pharmacol. 2019. https://doi.org/10.1007/ s11481-019-09834-5.

3. Torres-Rosas R, Yehia G, Pena G, Mishra P, del Rocio T-B, Moreno-Eutimio MA, Arriaga-Pizano LA, Isibasi A, Ulloa L. Dopamine mediates vagal modulation of the immune system by electroacupuncture. Nat Med. 2014;20:291-5.

4. Shao W, Zhang SZ, Tang M, Zhang XH, Zhou Z, Yin YQ, Zhou QB, Huang YY, Liu YJ, Wawrousek E, et al. Suppression of neuroinflammation by astrocytic dopamine D2 receptors via alphaB-crystallin. Nature. 2013:494:90-4.

5. Yan Y, Jiang W, Liu L, Wang X, Ding C, Tian Z, Zhou R. Dopamine controls systemic inflammation through inhibition of NLRP3 inflammasome. Cell. 2015;160:62-73.

6. Oehlers SH, Flores MV, Hall CJ, Wang L, Ko DC, Crosier KE, Crosier PS. A whole animal chemical screen approach to identify modifiers of intestinal neutrophilic inflammation. FEBS J. 2017;284:402-13.

7. Tolstanova G, Deng X, Ahluwalia A, Paunovic B, Prysiazhniuk A, Ostapchenko L, Tarnawski A, Sandor Z, Szabo S. Role of dopamine and D2 dopamine receptor in the pathogenesis of inflammatory bowel disease. Dig Dis Sci. 2015;60:2963-75.

8. Khan OA, Olek MJ. Treatment of paroxysmal symptoms in multiple sclerosis with bromocriptine. J Neurol Neurosurg Psychiatry. 1995;58:253.

9. Dijkstra C, Rouppe Van der Voort E, De Groot C, Huitinga I, Uitdehaag B, Polman C, Berkenbosch F. Therapeutic effect of the D2-dopamine agonist bromocriptine on acute and relapsing experimental allergic encephalomyelitis. Psychoneuroendocrinology. 1994;19:8.

10. Elgueta D, Aymerich MS, Contreras F, Montoya A, Celorrio M, RojoBustamante E, Riquelme E, Gonzalez H, Vasquez M, Franco R, Pacheco R. Pharmacologic antagonism of dopamine receptor D3 attenuates neurodegeneration and motor impairment in a mouse model of Parkinson's disease. Neuropharmacology. 2017;113:110-23.

11. Elgueta D, Contreras F, Prado C, Montoya A, Ugalde V, Chovar O, Villagra R, Henriquez C, Abellanas MA, Aymerich MS, et al. Dopamine receptor D3 expression is altered in CD4+ T-cells from Parkinson's disease patients and its pharmacologic inhibition attenuates the motor impairment in a mouse model. Front Immunol. 2019. https://doi.org/10.3389/fimmu.2019. 00981.

12. Gonzalez H, Contreras F, Prado C, Elgueta D, Franz D, Bernales S, Pacheco R. Dopamine receptor D3 expressed on CD4+ T cells favors neurodegeneration of dopaminergic neurons during Parkinson's disease. J Immunol. 2013:190:5048-56.
13. Gonzalez H, Elgueta D, Montoya A, Pacheco R. Neuroimmune regulation of microglial activity involved in neuroinflammation and neurodegenerative diseases. J Neuroimmunol. 2014:274:1-13.

14. Contreras F, Prado C, Gonzalez H, Franz D, Osorio-Barrios F, Osorio F, Ugalde V, Lopez E, Elgueta D, Figueroa A, et al. Dopamine receptor D3 signaling on CD4+ T cells favors Th1- and Th17-mediated immunity. J Immunol. 2016:196:4143-9.

15. Ugalde V, Contreras F, Prado C, Chovar O, Espinoza A, Pacheco R. Dopaminergic signalling limits suppressive activity and gut homing of regulatory T cells upon intestinal inflammation. Mucosal Immunol. 2021;14:652-66.

16. Wang W, Cohen JA, Wallrapp A, Trieu KG, Barrios J, Shao F, Krishnamoorthy $\mathrm{N}$, Kuchroo VK, Jones MR, Fine A, et al. Age-related dopaminergic innervation augments Thelper 2-type allergic inflammation in the postnatal lung. Immunity. 2019;51:1102-1118 e1107

17. Prado C, Bernales S, Pacheco R. Modulation of T-cell mediated immunity by dopamine receptor d5. Endocr Metab Immune Disord Drug Targets. 2013:13:184-94.

18. Prado C, Contreras F, Gonzalez H, Diaz P, Elgueta D, Barrientos M, Herrada AA, Lladser A, Bernales S, Pacheco R. Stimulation of dopamine receptor D5 expressed on dendritic cells potentiates Th17-mediated immunity. J Immunol. 2012;188:3062-70.

19. Prado C, Gaiazzi M, Gonzalez H, Ugalde V, Figueroa A, Osorio-Barrios FJ, Lopez E, Lladser A, Rasini E, Marino F, et al. Dopaminergic stimulation of myeloid antigen-presenting cells attenuates signal transducer and activator of transcription 3-activation favouring the development of experimental autoimmune encephalomyelitis. Front Immunol. 2018:9:571.

20. Osorio-Barrios F, Prado C, Contreras F, Pacheco R. Dopamine receptor D5 signaling plays a dual role in experimental autoimmune encephalomyelitis potentiating Th17-mediated immunity and favoring suppressive activity of regulatory T-cells. Front Cell Neurosci. 2018;12:192.

21. Balkowiec-Iskra E, Kurkowska-Jastrzebska I, Joniec I, Ciesielska A, Czlonkowska A, Czlonkowski A. Dopamine, serotonin and noradrenaline changes in the striatum of C57BL mice following myelin oligodendrocyte glycoprotein (MOG) 35-55 and complete Freund adjuvant (CFA) administration. Acta Neurobiol Exp (Wars). 2007;67:379-88.

22. Balkowiec-Iskra E, Kurkowska-Jastrzebska I, Joniec I, Ciesielska A, Muszynska A, Przybylkowski A, Czlonkowska A, Czlonkowski A. MPTP-induced central dopamine depletion exacerbates experimental autoimmune encephalomyelitis (EAE) in C57BL mice. Inflamm Res. 2007:56:311-7.

23. Matt SM, Gaskill PJ. Where is dopamine and how do immune cells see it?: Dopamine-mediated immune cell function in health and disease. J Neuroimmune Pharmacol. 2020;15:114-64.

24. Cosentino M, Zaffaroni M, Trojano M, Giorelli M, Pica C, Rasini E, Bombelli R, Ferrari M, Ghezzi A, Comi G, et al. Dopaminergic modulation of CD4+CD25(high) regulatory $T$ lymphocytes in multiple sclerosis patients during interferon-beta therapy. NeurolmmunoModulation. 2012;19:283-92.

25. Marino F, Cosentino M. Multiple sclerosis: repurposing dopaminergic drugs for MS - the evidence mounts. Nat Rev Neurol. 2016;12:191-2.

26. Montoya A, Elqueta D, Campos J, Chovar O, Falcon P, Matus S, Alfaro I, Bono MR, Pacheco R. Dopamine receptor D3 signalling in astrocytes promotes neuroinflammation. J Neuroinflammation. 2019:16:258.

27. Claes N, Fraussen J, Stinissen P, Hupperts R, Somers V. B cells are multifunctional players in multiple sclerosis pathogenesis: insights from therapeutic interventions. Front Immunol. 2015;6:642.

28. Lehmann-Horn K, Kronsbein HC, Weber MS. Targeting B cells in the treatment of multiple sclerosis: recent advances and remaining challenges. Ther Adv Neurol Disord. 2013;6:161-73.

29. Linington C, Bradl M, Lassmann $H$, Brunner C, Vass K. Augmentation of demyelination in rat acute allergic encephalomyelitis by circulating mouse monoclonal antibodies directed against a myelin/oligodendrocyte glycoprotein. Am J Pathol. 1988;130:443-54

30. von Budingen HC, Palanichamy A, Lehmann-Horn K, Michel BA, Zamvil SS. Update on the autoimmune pathology of multiple sclerosis: B-cells as disease-drivers and therapeutic targets. Eur Neurol. 2015;73:238-46.

31. Hauser S, Waubant E, Arnold D, Vollmer T, Antel J, Fox R, Bar-Or A, Panzara M, Sarkar N, Agarwal S, et al. B-cell depletion with rituximab in relapsingremitting multiple sclerosis. N Engl J Med. 2008;358:13.

32. Hawker K, O'Connor P, Freedman MS, Calabresi PA, Antel J, Simon J, Hauser S, Waubant E, Vollmer T, Panitch H, et al. Rituximab in patients with 
primary progressive multiple sclerosis: results of a randomized doubleblind placebo-controlled multicenter trial. Ann Neurol. 2009;66:460-71.

33. Sabatino JJ Jr, Probstel AK, Zamvil SS. B cells in autoimmune and neurodegenerative central nervous system diseases. Nat Rev Neurosci. 2019;20:728-45.

34. Fillatreau S, Sweenie CH, McGeachy MJ, Gray D, Anderton SM. B cells regulate autoimmunity by provision of IL-10. Nat Immunol. 2002;3:944-50.

35. Matsushita T, Yanaba K, Bouaziz JD, Fujimoto M, Tedder TF. Regulatory B cells inhibit EAE initiation in mice while other $B$ cells promote disease progression. J Clin Invest. 2008;1 18:3420-30.

36. Wu GF, Shindler KS, Allenspach EJ, Stephen TL, Thomas HL, Mikesell RJ, Cross AH, Laufer TM. Limited sufficiency of antigen presentation by dendritic cells in models of central nervous system autoimmunity. J Autoimmun. 2011;36:56-64.

37. Parker Harp CR, Archambault AS, Sim J, Ferris ST, Mikesell RJ, Koni PA, Shimoda M, Linington C, Russell JH, Wu GF. B cell antigen presentation is sufficient to drive neuroinflammation in an animal model of multiple sclerosis. J Immunol. 2015;194:5077-84.

38. Molnarfi N, Schulze-Topphoff U, Weber MS, Patarroyo JC, Prod'homme T, Varrin-Doyer M, Shetty A, Linington C, Slavin AJ, Hidalgo J, et al. MHC class II-dependent B cell APC function is required for induction of CNS autoimmunity independent of myelin-specific antibodies. J Exp Med. 2013;210:2921-37.

39. Parker Harp CR, Archambault AS, Sim J, Shlomchik MJ, Russell JH, Wu GF. B cells are capable of independently eliciting rapid reactivation of encephalitogenic CD4 T cells in a murine model of multiple sclerosis. PLOS ONE. 2018;13: e0199694.

40. Pierson ER, Stromnes IM, Goverman JM. B cells promote induction of experimental autoimmune encephalomyelitis by facilitating reactivation of T cells in the central nervous system. J Immunol. 2014;192:929-39.

41. Barr TA, Shen P, Brown S, Lampropoulou V, Roch T, Lawrie S, Fan B, O'Connor RA, Anderton SM, Bar-Or A, et al. B cell depletion therapy ameliorates autoimmune disease through ablation of IL-6-producing B cells. J Exp Med. 2012;209:1001-10.

42. Lehmann-Horn K, Kinzel S, Weber MS. Deciphering the role of B cells in multiple sclerosis-towards specific targeting of pathogenic function. Int J Mol Sci. 2017. https://doi.org/10.3390/ijms18102048.

43. Marta CB, Oliver AR, Sweet RA, Pfeiffer SE, Ruddle NH. Pathogenic myelin oligodendrocyte glycoprotein antibodies recognize glycosylated epitopes and perturb oligodendrocyte physiology. Proc Natl Acad Sci U S A. 2005;102:13992-7.

44. Oliver AR, Lyon GM, Ruddle NH. Rat and human myelin oligodendrocyte glycoproteins induce experimental autoimmune encephalomyelitis by different mechanisms in C57BL/6 mice. J Immunol. 2003:171:462-8.

45. Clements CS, Reid HH, Beddoe T, Tynan FE, Perugini MA, Johns TG, Bernard CC, Rossjohn J. The crystal structure of myelin oligodendrocyte glycoprotein, a key autoantigen in multiple sclerosis. Proc Natl Acad Sci U S A. 2003;100:11059-64.

46. Hausler D, Hausser-Kinzel S, Feldmann L, Torke S, Lepennetier G, Bernard CCA, Zamvil SS, Bruck W, Lehmann-Horn K, Weber MS. Functional characterization of reappearing $B$ cells after anti-CD20 treatment of CNS autoimmune disease. Proc Natl Acad Sci U S A. 2018;115:9773-8.

47. Weber MS, Prod'homme T, Patarroyo JC, Molnarfi N, Karnezis T, LehmannHorn K, Danilenko DM, Eastham-Anderson J, Slavin AJ, Linington C, et al. B-cell activation influences T-cell polarization and outcome of anti-CD20 B-cell depletion in central nervous system autoimmunity. Ann Neurol. 2010:68:369-83

48. McKenna F, McLaughlin PJ, Lewis BJ, Sibbring GC, Cummerson JA, BowenJones D, Moots RJ. Dopamine receptor expression on human T- and B-lymphocytes, monocytes, neutrophils, eosinophils and NK cells: a flow cytometric study. J Neuroimmunol. 2002;132:34-40.

49. Pacheco R. Targeting dopamine receptor D3 signalling in inflammation. Oncotarget. 2017;8:7224-5.

50. Joseph JD, Wang YM, Miles PR, Budygin EA, Picetti R, Gainetdinov RR, Caron MG, Wightman RM. Dopamine autoreceptor regulation of release and uptake in mouse brain slices in the absence of D(3) receptors. Neuroscience. 2002;112:39-49.

51. Moore C, Tejon G, Fuentes C, Hidalgo Y, Bono MR, Maldonado P, Fernan$\operatorname{dez} \mathrm{R}$, Wood KJ, Fierro JA, Rosemblatt M, et al. Alloreactive regulatory T cells generated with retinoic acid prevent skin allograft rejection. Eur J Immunol. 2015;45:452-63.
52. Zheng Y, Yu M, Padmanabhan A, Aster RH, Yuan L, Wen R, Wang D. Critical role of CD4 T cells in PF4/heparin antibody production in mice. Blood. 2015:125:1826-9.

53. Obino D, Fetler L, Soza A, Malbec O, Saez JJ, Labarca M, Oyanadel C, DelValle Batalla F, Goles N, Chikina A, et al. Galectin-8 favors the presentation of surface-tethered antigens by stabilizing the B cell immune synapse. Cell Rep. 2018;25:3110-3122 e3116.

54. Bettelli E, Sullivan B, Szabo SJ, Sobel RA, Glimcher LH, Kuchroo VK. Loss of T-bet, but not STAT1, prevents the development of experimental autoimmune encephalomyelitis. J Exp Med. 2004;200:79-87.

55. Evans JG, Chavez-Rueda KA, Eddaoudi A, Meyer-Bahlburg A, Rawlings DJ, Ehrenstein MR, Mauri C. Novel suppressive function of transitional $2 \mathrm{~B}$ cells in experimental arthritis. J Immunol. 2007;178:7868-78.

56. Kitamura D, Roes J, Kuhn R, Rajewsky K. A B cell-deficient mouse by targeted disruption of the membrane exon of the immunoglobulin mu chain gene. Nature. 1991;350:423-6.

57. Codarri L, Gyulveszi G, Tosevski V, Hesske L, Fontana A, Magnenat L, Suter T, Becher B. RORgammat drives production of the cytokine GM-CSF in helper T cells, which is essential for the effector phase of autoimmune neuroinflammation. Nat Immunol. 2011;12:560-7.

58. Papa I, Saliba D, Ponzoni M, Bustamante S, Canete PF, Gonzalez-Figueroa P, McNamara HA, Valvo S, Grimbaldeston M, Sweet RA, et al. TFH-derived dopamine accelerates productive synapses in germinal centres. Nature. 2017:547:318-23.

59. Saraste M, Penttila TL, Airas L. Natalizumab treatment leads to an increase in circulating CXCR3-expressing B cells. Neurol Neuroimmunol Neuroinflamm. 2016;3: e292.

60. Ruprecht CR, Lanzavecchia A. Toll-like receptor stimulation as a third signal required for activation of human naive B cells. Eur J Immunol. 2006;36:810-6

61. Jegerlehner A, Maurer P, Bessa J, Hinton HJ, Kopf M, Bachmann MF. TLR9 signaling in $B$ cells determines class switch recombination to IgG2a. J Immunol. 2007;178:2415-20.

62. Rubtsova K, Rubtsov AV, Thurman JM, Mennona JM, Kappler JW, Marrack P. B cells expressing the transcription factor T-bet drive lupus-like autoimmunity. J Clin Invest. 2017;127:1392-404.

63. van Langelaar J, Rijvers $L$, Janssen $M$, Wierenga-Wolf AF, Melief MJ, Siepman TA, de Vries HE, Unger PA, van Ham SM, Hintzen RQ, van Luijn MM. Induction of brain-infiltrating T-bet-expressing B cells in multiple sclerosis. Ann Neurol. 2019:86:264-78.

64. Bettelli E, Baeten D, Jager A, Sobel RA, Kuchroo VK. Myelin oligodendrocyte glycoprotein-specific T and B cells cooperate to induce a Devic-like disease in mice. J Clin Invest. 2006;1 16:2393-402.

65. Krishnamoorthy G, Lassmann H, Wekerle H, Holz A. Spontaneous opticospinal encephalomyelitis in a double-transgenic mouse model of autoimmune T cell/B cell cooperation. J Clin Invest. 2006;116:2385-92.

66. Craft JE. Follicular helper T cells in immunity and systemic autoimmunity. Nat Rev Rheumatol. 2012;8:337-47.

67. Serre K, Cunningham AF, Coughlan RE, Lino AC, Rot A, Hub E, Moser K, Manz R, Ferraro A, Bird R, et al. CD8 T cells induce T-bet-dependent migration toward CXCR3 ligands by differentiated $B$ cells produced during responses to alum-protein vaccines. Blood. 2012;120:4552-9.

68. Matsushita T, Horikawa M, Iwata Y, Tedder TF. Regulatory B cells (B10 cells) and regulatory $T$ cells have independent roles in controlling experimental autoimmune encephalomyelitis initiation and late-phase immunopathogenesis. J Immunol. 2010;185:2240-52.

69. Matsumoto M, Baba A, Yokota T, Nishikawa H, Ohkawa Y, Kayama H, Kallies A, Nutt SL, Sakaguchi S, Takeda K, et al. Interleukin-10-producing plasmablasts exert regulatory function in autoimmune inflammation. Immunity. 2014;41:1040-51.

70. Yednock TA, Cannon C, Fritz LC, Sanchez-Madrid F, Steinman L, Karin N. Prevention of experimental autoimmune encephalomyelitis by antibodies against alpha 4 beta 1 integrin. Nature. 1992;356:63-6.

71. Lehmann-Horn K, Sagan SA, Bernard CC, Sobel RA, Zamvil SS. B-cell very late antigen- 4 deficiency reduces leukocyte recruitment and susceptibility to central nervous system autoimmunity. Ann Neurol. 2015;77:902-8.

72. Glatigny S, Wagner CA, Bettelli E. Cutting edge: integrin alpha4 is required for regulatory B cell control of experimental autoimmune encephalomyelitis. J Immunol. 2016;196:3542-6. 
73. Lublin FD, Cutter G, Giovannoni G, Pace A, Campbell NR, Belachew S. Natalizumab reduces relapse clinical severity and improves relapse recovery in MS. Mult Scler Relat Disord. 2014;3:705-11.

74. Basova L, Najera JA, Bortell N, Wang D, Moya R, Lindsey A, Semenova $S$, Ellis RJ, Marcondes MCG. Dopamine and its receptors play a role in the modulation of CCR5 expression in innate immune cells following exposure to Methamphetamine: implications to HIV infection. PLoS ONE. 2018;13: e0199861.

75. Espinosa-Oliva AM, de Pablos RM, Sarmiento M, Villaran RF, CarrilloJimenez A, Santiago M, Venero JL, Herrera AJ, Cano J, Machado A. Role of dopamine in the recruitment of immune cells to the nigro-striatal dopaminergic structures. Neurotoxicology. 2014;41:89-101.

76. Watanabe Y, Nakayama T, Nagakubo D, Hieshima K, Jin Z, Katou F, Hashimoto K, Yoshie O. Dopamine selectively induces migration and homing of naive CD8+ T cells via dopamine receptor D3. J Immunol. 2006;176:9.

77. Kipnis J, Cardon M, Avidan H, Lewitus GM, Mordechay S, Rolls A, Shani Y, Schwartz M. Dopamine, through the extracellular signal-regulated kinase pathway, downregulates $C D 4+C D 25+$ regulatory T-cell activity: implications for neurodegeneration. J Neurosci. 2004;24:6133-43.

78. Osorio-Barrios F, Navarro G, Campos J, Ugalde V, Prado C, Raich I, Contreras F, Lopez E, Espinoza A, Lladser A, et al. The heteromeric complex formed by dopamine receptor D5 and CCR9 leads the gut homing of CD4(+) T cells upon inflammation. Cell Mol Gastroenterol Hepatol. 2021;12:489-506.

79. Benson CA, Wong G, Tenorio G, Baker GB, Kerr BJ. The MAO inhibitor phenelzine can improve functional outcomes in mice with established clinical signs in experimental autoimmune encephalomyelitis (EAE). Behav Brain Res. 2013;252:302-11.

\section{Publisher's Note}

Springer Nature remains neutral with regard to jurisdictional claims in published maps and institutional affiliations.

- fast, convenient online submission

- thorough peer review by experienced researchers in your field

- rapid publication on acceptance

- support for research data, including large and complex data types

- gold Open Access which fosters wider collaboration and increased citations

- maximum visibility for your research: over $100 \mathrm{M}$ website views per year

At BMC, research is always in progress.

Learn more biomedcentral.com/submissions 